Revista lus et Praxis, Año 18, № 1, 2012, pp. 113 - 150

ISSN 0717 - 2877

Universidad de Talca - Facultad de Ciencias Jurídicas y Sociales

“¿Por qué aumenta la población penal en Chile?

Un estudio criminológico longitudinal"

Sebastián Salinero Echeverría

\title{
¿POR QUÉ AUMENTA LA POBLACIÓN PENAL EN CHILE? UN ESTUDIO CRIMINOLÓGICO LONGITUDINAL*
}

\author{
¿WHY IS CRIMINAL POPULATION INCREASING IN CHILE? \\ A LONGITUDINAL CRIMINOLOGY STUDY
}

Sebastián Salinero EcheverRía**

RESUMEN

En este trabajo se analizan los factores y las respectivas causas del incremento de la población carcelaria en Chile entre el período 2000-2009. Se consigna que los factores que producirían la inflación penitenciaria son atribuibles al mayor ingreso de personas al sistema penal; al mayor tiempo de privación de libertad de los penados, y a la falta de mecanismos reales de descompresión carcelaria. A su vez, se analizan

las causas que probablemente originarían estos factores, tales como la Reforma Procesal Penal y todo lo que ella introdujo desde la perspectiva de un nuevo sistema de administración de justicia penal; el punitivismo penal, con leyes que favorecerían la prisionización, y un marcado reduccionismo en los denominados beneficios legales alternativos a la prisión.

ABSTRACT

In this paper the author analyzes the factors and causes of the increase in prison population in Chile between 2000 and 2009. It is stated that the factors that cause a rise in prison population are attributable to an increased inflow of people into the criminal system, to a longer incarceration of prisoners, and, to a lack of real mechanisms of prison reduction. In turn, the causes that are likely to originate these

factors are analyzed, such as the Criminal Procedure Reform and everything it brought from the perspective of a new system of criminal justice, the punitive criminal justice that favor incarceration, and a marked reduction in legal benefits known as alternatives to prison.

PALABRAS CLAVE

Población Penal, Factores y Causas, Cárceles

KEYWORDS

Prison population, Factors and causes, Prisons

* El autor agradece sinceramente las críticas y aportaciones de los profesores Dr. Raúl Carnevali, Dr. Francisco Maldonado y Mg. Ana María Morales. Trabajo recibido el 11 de octubre de 2011 y aprobado 20 de abril de 2012.

** Abogado, Magíster en Derecho Penal de la U. de Talca y Doctorando con Diploma de estudios avanzados en la U. de Lérida (España). Actual Investigador del Centro de Estudios de Derecho Penal de la Universidad de Talca. Correo electrónico: ssalinero@utalca.cl. 


\section{INTRODUCCIÓN}

La inflación carcelaria y la sobrepoblación penal son cosas distintas desde la óptica de la política penitenciaria. Mientras la primera designa el desfase que existe entre el incremento del número de población penal y el crecimiento demográfico de un país (número de habitantes del mismo); la segunda dice relación con la inadecuación en un tiempo determinado del total de la población detenida en los establecimientos penitenciarios y el número de plazas o camas disponibles en los mismos penales. ${ }^{1}$ La inflación es sinónimo de un incremento de la población penal en términos absolutos y de su tasa como coeficiente, en cambio, la sobrepoblación penal puede llegar a ser un efecto de la inflación.

Como señala Frey, esta inflación se puede producir por un incremento de los flujos de entrada a pesar que los tiempos de detención permanezcan estables o disminuyan; por un incremento en las duraciones de las detenciones, aunque los flujos de entrada a los penales sean estables o a la baja; o desde un punto de vista ecléctico, por el incremento simultáneo de los flujos de ingreso y de duración de las detenciones. ${ }^{2}$

El objetivo de este trabajo es determinar los factores -y sus causas- que han influido en la inflación de la población penal en Chile entre los años 2000 y 2009. Desde ya, anticipamos, que estimamos que se trata de multifactores y no de uno solo que justifique este fenómeno. Se han esgrimido diferentes razones que explicarían este ascenso, tales como el aumento en el delito, la entrada en vigencia de la Reforma Procesal Penal, el cambio en la política de aplicación de beneficios alternativos a la prisión e intrapenitenciarios, la dictación de una serie de leyes tendientes al favorecimiento de la prisionización, el endurecimiento de las penas de algunos delitos, etc.

Nos proponemos confirmar o desvirtuar las diferentes tesis y ver si el fenómeno acaba ahí o por el contrario existen otros factores y causas que podrían explicar este comportamiento o tendencia positiva.

La importancia de establecer las razones que motivan el inflación carcelaria no sólo radica en una necesidad etiológica, sino también en poder conocer y predecir si este fenómeno se presentará en forma temporal o permanente en el tiempo y si la infraestructura carcelaria -donde en la actualidad existe sobrepoblación penal-será suficiente para las nuevas demandas.

\footnotetext{
${ }^{1}$ FreY, Antonio, "Seguridad ciudadana, ambivalencia de las políticas criminológicas y privatización del sistema carcelario", Revista de la Academia 5 (2000), pp. 19-34, p. 26.

${ }^{2}$ Ibíd., p. 26.
} 


\section{EVOLUCIÓN DE LA POBLACIÓN PENITENCIARIA: AÑOS 2000-2009}

Según se advierte en el Gráfico 1, en la primera década de este siglo, la población penal en Chile, constituida tanto por: Detenidos, Procesados (antiguo sistema penal), Imputados (nuevo sistema penal) y los Condenados privados de libertad, experimentó un incremento en términos absolutos en orden al $54 \%{ }^{3}$

Cabe destacar que el aumento en la primera mitad de la década, alcanza apenas un $10 \%$, registrándose su mayor variación en la segunda mitad del lustro, con una subida de un 37,5\%.

Conforme al Balance de la Fundación Paz Ciudadana 2010, la tasa de población penal en nuestro país es de 305 personas (cada 100.000 personas) y ocuparía el tercer lugar en América del Sur, tras Guayana Francesa y Surinam. ${ }^{4}$

\section{Gráfico 1}

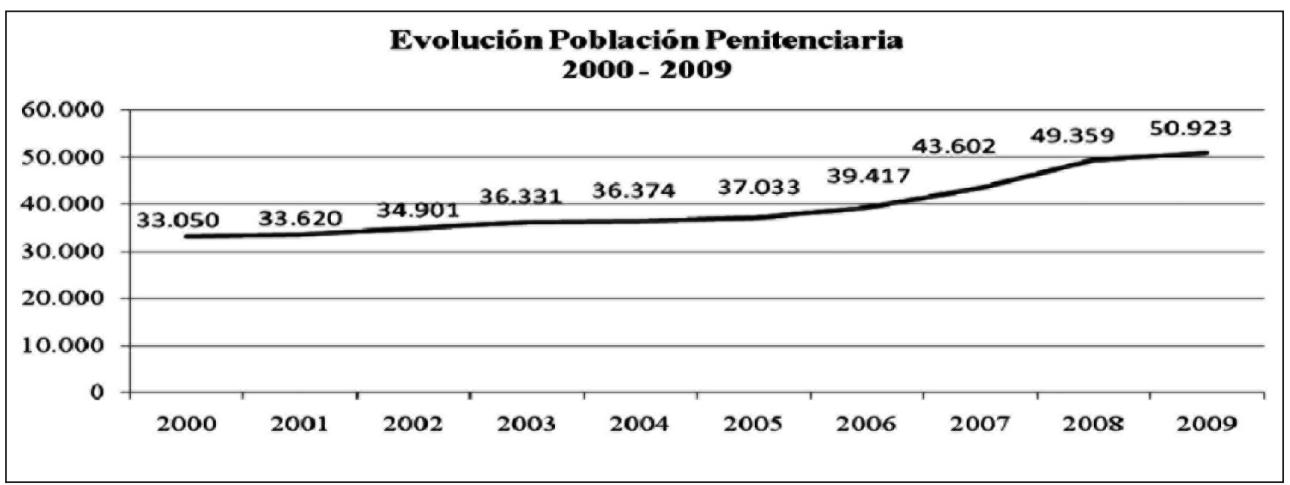

Fuente: Elaboración propia a partir de los datos obtenidos del Ministerio del Interior de Chile (División Seguridad Pública) y Fundación Paz Ciudadana.

\footnotetext{
${ }_{3}^{3}$ Para la Fundación Paz Ciudadana la variación para el mismo período es de 58,9\%, en Balance Delincuencia 2009, p. 19. En: http://www.pazciudadana.cl, [visitado el 22/03/11].

${ }^{4}$ Véase Fundación Paz Ciudadana. En: http://www.pazciudadana.cl [visitado el 22/06/11]. No obstante esta afirmación, estimamos que Chile es el país más encarcelador de la región; para el caso de Surinam, la tasa se estableció en el año 2005 y no corresponde al mismo año en que se determinó para Chile. Según Human Rights Report, esta nación a fines del año 2008 tenía un universo penitenciario de 915 personas. (Fuente U.S. Department. En: http://www.state.gov/g/drl/rls/hrrpt/2009/wha/136127. htm [visitado el 3/08/11]), lo cual refleja que su tasa real penitenciaria es de 146 personas por cada cien mil y no de 356 como se informa. Respecto de la Guayana Francesa, no es producible un análisis comparativo al no ser un país, sino que es territorio francés de ultramar. Si no se entiende así, podríamos comparar regiones y arribar a la absurda conclusión de que la Región de Atacama -población similar a la Guayana- tiene una tasa de población penal inmensamente superior a la Guayana en cuestión. En definitiva, Chile es el país más encarcelador de toda América del Sur; Para un análisis comparado, véase Dammert, Lucía-ZúÑiga, Liza, La Cárcel: Problemas y desafíos para las Américas, Flacso, Santiago de Chile, 2008.
} 
Para terminar, en el concierto mundial, de un total de 34 Estados miembros de la Organización para la Cooperación y Desarrollo Económico (OCDE), Chile en el año 2009 , se ubicó en el lugar $18^{\circ}$ de los países con más población penal. ${ }^{5}$

\section{El CARÁCTER CRÓNICO EN EL INCREMENTO DE LA POBLACIÓN CARCELARIA CHILENA:}

¿ES UN PROBLEMA DE ESTA DÉCADA?

Para el caso chileno, el aumento de la población penitenciaria no puede ser atribuido de manera exclusiva a los factores y causas que expondremos más adelante. A nuestro juicio, existen otras razones que de manera habitual han contribuido a esta tendencia alcista, que por el momento no tiene un horizonte definido que le ponga límite. Prueba de ello, es que desde comienzo de la década de los ochenta, hasta hoy, el aumento de la población penal se ha presentado como una constante que no detiene su rumbo.

En el año 1980, la población que se encontraba recluida en cárceles chilenas ascendía a 15.270 personas. Cinco años más tarde, en 1985, la población experimentó un alza de 33\% y su universo era de 20.242 personas. Para comienzos de la década de los noventa, la tendencia alcista seguía como máxima, encontrándose recluidas 22.593 personas. ${ }^{6}$ Luego, a mediados del segundo lustro de esa década, o sea, en el año 1998, la cantidad de personas que se encontraban encarceladas era de 26.871. En síntesis, sólo en la década del ochenta el incremento de la población carcelaria fue de un $65 \%$, en circunstancias que la población chilena sólo tuvo un incremento nominal de un $16 \%$. Por su parte, en la década de los noventa, la variación carcelaria total del período fue de un $33 \%$, siendo el crecimiento poblacional total del país de un 16,5\%. ${ }^{7}$

Las probables razones de este endémico incremento carcelario las podemos hallar en dos tipos de causas que hemos denominado legales y político-sociales. La primera, está comprendida por un conjunto de leyes que han producido un doble efecto: por una parte, contribuir al ingreso de un mayor número de personas a prisión y, por otra, favorecer el cumplimiento de penas privativas de libertad más largas en su duración. Podrían ser prueba de aquello, la modificación que desde la década de los cincuenta vienen recibiendo los delitos contra la propiedad, los que sin duda alguna cuentan con mayor representación en la

\footnotetext{
${ }^{5}$ Véase International Centre for Prision Studies, King's College, London 2010. En: http://www.kcl.ac.uk/ depsta/law/research/icps/worldbrief/ [visitado el 22/06/11].

${ }^{6}$ Los datos estadísticos correspondientes a la década del ochenta y los noventa fueron obtenidos desde la Fundación Paz Ciudadana y Ministerio de Justicia, en documento de trabajo Propuesta para reforma al sistema de medidas alternativas a la privación de libertad, febrero de 2001. En: http://cejamericas.xred.com [visitado el 10/06/11].

${ }^{7}$ El crecimiento poblacional se calculó en base al texto emanado del Instituto Nacional de Estadísticas Chile: Proyecciones y estimaciones de población. Total país 1950-2050. En: www.ine.cl [visitado el 22/06/11].
} 
distribución de la geografía carcelaria (más del 50\% de la población penal). ${ }^{8}{ }^{8} 9$ La segunda causa, esto es, las político-sociales que incidirían en el incremento penitenciario, las que por lo demás entendemos como intrínsecas a este complejo problema y quizás le acompañen en el devenir de los próximos años, pudiesen estar relacionadas con la tesis del finés Lappi-Seppala, el que esgrime que las políticas de castigo y las altas tasas de encarcelamiento que de ellas provienen, estarían relacionadas con tres factores: bienestar social, igualdad y punitividad; confianza de los ciudadanos entre ellos y respecto de las autoridades, los miedos individuales y las demandas de control social, y la cultura política en conflicto frente a los consensos. ${ }^{10}$

\section{El Delito COMO EXPLICACIÓN DEL AUMENTO DE LA POBLACIÓN PENAL}

Sería lógico pensar que el incremento de la población penal encuentra sus causas en el aumento de la delincuencia, en especial en el alza del delito registrado. Sin embargo, las tasas de encarcelamiento no guardan relación con las tasas de victimización proveidas por las encuestas oficiales o por los delitos registrados a traves de la denuncia a los organismos oficiales (Policías y Ministerio Público).

En Lappi-Seppala, ${ }^{11}$ se demostró que para 25 países -extraídos desde Europa del Sur, Europa del Este, Escandinavia, más EE.UU. y Canadá-, el desarrollo de las tasas de encarcelamiento entre 1980 y 2005, no mostraron patrones consistentes con el total de delitos registrados. Estos países mostraron patrones de coportamiento diversos en tiempos diferentes. Esto encaja con la literatura especializada, en orden a establecer que la prisión apenas se ve afectada por los niveles y tendencias de la delincuenacia. ${ }^{12}$

\footnotetext{
${ }^{8}$ Con carácter meramente ejemplar, la ley № 11.625, de octubre de 1954, estableció una nueva regulación de las hipótesis calificadas o agravadas de robo y aumentó la penalidad (estableció una pena única de 5 años y 1 día a 20 años de presidio), cualquiera que fuera el valor de la cosa objeto del robo.

${ }^{9}$ En palabras de Bascuñán Rodríguez, el objetivo político-criminal de esta ley fue aumentar la penalidad del delito de robo y al mismo tiempo simplificar el régimen legal de determinación de dicha penalidad. Bascuñán Rodríguez, Antonio, "El robo como coacción", Revista de Estudio de la Justicia 1 (2002), pp. 55-125, p. 80; ley $N^{\circ} 17.727$, de septiembre de 1972, vino a adelantar los efectos punitivos de una serie de delitos contra la propiedad (robo con violencia e intimidación y robo con fuerza efectuado en lugar habitado) castigándolos como consumados desde que se encuentran en grado de tentativa.

${ }^{10}$ Lappi Seppala, Tapio, "Trust, Welfare, and Political Culture: Explaining Differences in National Penal Policies", en The University of Chicago Crime and Justice 37 (2008), pp.313-387.

${ }^{11}$ Lappl Seppala, Tapio, cit. nota n. 10, p. 342.

${ }^{12}$ Véase Greenber, David, "Punishment, Division of Labor, and Social Solidarity", The Criminology of Criminal Law. Advances in Criminology Theory 8 (1999), pp. 283-361; Von Hofer, Hanns, "Prision Populations as Political Constructs: The case of Finland, Holand and Sweden", en Journal of Sandinavian Studies in Criminology and Crime Prevention 4 (2003), pp. 21-38; Sutton, John, "The Political Economy of
} 
La encuesta europea sobre criminalidad y seguridad del 2005 viene a confirmar la independencia entre la evolución de la criminalidad y el encarcelamiento. La comparación entre los diversos países resulta una vez más muy útil a este efecto, pues en un contexto general de la reducción de la criminalidad en Europa la población penitenciaria evoluciona de modo distinto en los diversos países. ${ }^{13}$

\section{Tabla 1. Evolución población penal, denuncia (DMCS) y victimización entre 2000-2009}

\begin{tabular}{|l|c|c|c|}
\hline Año & Población penal & Denuncia & Victimización \\
\hline 2000 & 33.050 & 218.481 & - \\
\hline 2001 & 33.620 & 263.740 & - \\
\hline 2002 & 34.901 & 294.529 & - \\
\hline 2003 & 36.331 & 357.619 & 43 \\
\hline 2004 & 36.374 & 399.507 & No hay \\
\hline 2005 & 37.033 & 407.000 & 38,3 \\
\hline 2006 & 39.417 & 409.093 & 38,4 \\
\hline 2007 & 43.602 & 442.789 & 34,8 \\
\hline 2008 & 49.359 & 455.070 & 35,3 \\
\hline 2009 & 50.923 & 489.197 & 33,6 \\
\hline
\end{tabular}

Fuente. Elaboración propia a partir de los datos de Gendarmería de Chile (Compendio Estadístico), División seguridad pública (Estadística denuncias) y Encuesta Nacional Urbana de Seguridad Ciudadana (ENUSC). ${ }^{14}$

En Chile, creemos con cierto duda que el panorama no es muy distinto al internacional. Si bien hace muy pocos años nuestras autoridades se encuentran

Imprisonment in Affluent Western Democracies, 1960-1990", en American Sociological Review 69 (2004), pp.170-189; RUdDELL, Rick, "Social Disruption, State Priorities, and Minority Threat: A Cross-National Study of Imprisonment", en Punishment and Society: The International Journal of Penology 7 (2005), pp. 7-28; MATHIESEN, Thomas, Juicio a la prisión, traducción de Zamuner Amanda Zamuner, Ediar, Buenos Aires, 2003, p. 44; Aebi y Kuhn analizaron, para algunos países europeos, la relación existente entre cada "tasa de encarcelamiento" y tres diferentes variables: "tasa de delincuencia", "número de condenas a prisión impuestas" y "duración de las mismas". Sus resultados reflejaron que no existe correlación entre la tasa de encarcelamiento y la tasa de de delincuencia o, cuando existe, es negativa y de escasa significancia. AeBI, Marcelo; Kunn, André, "Influences on the prisioners rate: Number of entries into prison lenght of sentences and crime rate", en European Journal on Criminal Policy and Research 8 (2000), pp. 65-75.

${ }^{13}$ VAN DIIK, Teun, "The Burden of crime in the E.U. 2005", p. 63. En: www.europeansafetyobservatory. eu/ [visitado el 10/06/11].

${ }^{14}$ La encuesta comenzó el año 2003, pero no se realizó el año 2004. Actualmente se hace todos los años. 
midiendo la delincuencia con un instrumento criminológicamente idóneo, como lo es la Encuesta de victimización, ${ }^{15}$ ésta, y la denuncia como medio de registro de la criminalidad (de los denominados delitos de mayor connotación social $)^{16}$, reflejan la misma orientación de países europeos: la prisión no guarda relación con las variaciones de la delincuencia. ${ }^{17}$

Esta tendencia mundial también se refleja en nuestro país. Como se advierte en la Tabla 1, mientras la victimización registra año a año un descenso, anotando en el período 2003-2009 una variación negativa de un -22\%; la denuncia de los denominados delitos de connotación social reporta un alza en términos absolutos de un $124 \%$ (la tasa de denuncia registra para igual período un $+70 \%$ ).

Las dudas que tenemos, se podrían generar con lo ocurrido en períodos anteriores, donde existe una aparente correlación positiva entre incremento del registro del delito denunciado y población penal. Si embargo, a esa época no se medía victimización con una encuesta, por lo que el análisis carece de todos los elementos necesarios para arribar a alguna conclusión categórica sobre el tema. ${ }^{18}$

\section{DiagnÓSTICO SOBRE LOS FACTORES ESPECÍfICOS DEL INCREMENTO}

DE LA POBLACIÓN PENAL

Anteriormente, explicamos en cifras el exponencial aumento de la población penal entre los años 2000 y 2009, intentamos dar cuenta que ese fenómeno no es aislado, sino que ha sido una tendencia cronica desde, a lo menos, la década de los ochenta, y que encontraría su origen en diversos

\footnotetext{
${ }^{15}$ Denominada en nuestro país: Encuesta Nacional Urbana de Seguridad Ciudadana (ENUSC).

${ }^{16}$ Delitos de Mayor Connotación Social (DMCS). Se consideran así a los delitos de robo con fuerza, robo con violencia, robo con intimidación, robo por sorpresa, hurto, lesiones, homicidio y violación.
}

${ }^{17}$ A nuestro entender, la delincuencia la podemos medir correctamente con la encuesta de victimización. En Criminología, en general, se critica la denuncia como medio idóneo de registro de la delincuencia, en razón de no ser una variable exógena, sino más bien endógena al problema delictual, lo cual, impediría la existencia de imparcialidad o produciría cierto sesgo en la mensura de la criminalidad. La denuncia puede estar condicionada por múltiples factores, como, por ejemplo: En el caso hipotético que aumente las pólizas de seguros, es probable que aumenten las denuncias como requisito para cobrar una indemnización. También puede estar condicionada por las facilidades que exista para denunciar, por ejemplo, la utilización del teléfono o Internet. Véase: Garrido, Vicente; Stangeland, Per - Redondo, Santiago, Principios de Criminología, $3^{\text {a }}$ edición, Tirant Lo Blanch, Valencia, 2006, p. 124; En ese mismo sentido: Stangeland, Per, "Encuestas de Victimización", en Díez Ripollés, José Luis; Cerezo Dominguez, Ana Isabel (editores). Los Problemas de la Investigación Empírica en Criminología: La situación española, Tirant Lo Blanch, Valencia, 2001, p. 12.

${ }^{18}$ A partir del año 1997 hasta el 2003, existió un aumento importante relativamente similar entre las denuncias de los delitos de mayor connotación social y la población penal. 
factores. Asimismo, reseñamos que estimabamos que el aumento de la población penal no encontraba su correlato en el aumento del delito, para lo cual justificabamos esta afirmación en las cifras expuestas y en la literartura extranjera que había estudiado esta relación. Pues bien, toca ahora señalar cuáles son los factores y las causas que motivarían el particular incremento de las personas privadas de libertad en la primera década de este siglo y que nos planteamos como hipótesis de trabajo.

Anteriormente, denominamos factores del incremento penitenciario y no meramente causas del fenómeno, porque el primero favorece o facilita esta situación. En cambio, las causas producirían directamente la ocurrencia del factor en cuestión. Dicho de otra manera, las causas son los motivos de los factores, quienes, a su vez, son los probables medios que inciden en el aumento de la población carcelaria.

Aclarado lo anterior, podemos señalar que las plausibles respuestas ante esta tendencia positiva las podemos atribuir a tres factores: a) En primer lugar, la existencia de un mayor flujo de ingresos al sistema penitenciario que no guardaría la debida correspondencia con las personas que egresan del mismo; b) En segundo término, también sería un factor que justificaría esta inflación, el hecho que algunas personas para determinados delitos ingresarían al sistema penitenciario y permanecerían largos tiempos de privación libertad en comparación a lo que sucedía en décadas pasadas, y c) Por último, un tercer factor que está conexo con los anteriores, es la falta de mecanismos eficientes que ayuden descomprimir el sistema carcelario.

Todos estos factores, impiden la debida rotación en el sistema carcelario. Entendiendo por tal, el hecho que la cárcel se sustenta desde una perspectiva funcional, en la mecánica que el número de personas que ingresan a la cárcel sea relativamente parecido o menor al número de personas que egresan de ella. Si no ocurre aquello, se genera una constante escasez de plazas carcelarias, motivando, por una parte, la sobrepoblación penal y, por otra, la necesidad de construir nuevos espacios de inocuización donde las personas puedan cumplir sus penas privativas de libertad o permanecer durante el tiempo de privación preventiva.

Como lo señalamos previamente, cada uno de estos tres factores, es motivado a su vez, por una serie de causas. Así, el mayor ingreso de personas al sistema penitenciario estaría dado a nuestro entender por dos causas que estimamos bien identificadas. Éstas serían la entrada en vigencia de la Reforma Procesal Penal y algunas leyes que favorecen la prisionización.

A su vez, las causas que producen que los ingresados al sistema penal permanezcan mayores tiempos sirviendo una pena son algunas leyes que han agravado o hecho más severas la punición de ciertos y determinados delitos muy bien representados en la geografía penitenciaria. 
Por último, nos referimos a factores conexos para nominar aquellas causas que impiden la adecuada descompresión del sistema carcelario y que estarían representadas por una aparente aplicación restringida de los beneficios alternativos a las penas privativas de libertad -remisión condicional de la pena, reclusión nocturna y libertad vigilada- y el beneficio penitenciario de la libertad condicional. Todo sin perjuicio, de carecer la institucionalidad vigente de mecanismos idóneos para destrabar las cárceles.

\section{Primer factor: Un mayor INGReso de PERSONAS AL SISTEMA PENITENCIARIO}

Es utópico pensar que la inflación penitenciaria y consecuente la sobrepoblación en los penales chilenos es un hecho aislado que se fundamentaría en determinadas circunstancias que motivan este fenómeno. La realidad de las cosas -o mejor dicho las cifras de las estadísticas oficiales-, parece demostrar que el incremento de los presos es la lógica consecuencia de una sistemática y prolongada desconexión entre los flujos de entrada y salida de los condenados a una pena privativa de libertad o sujetos a prisión preventiva.

La Tabla 2 refleja que entre los años 1997-2009 la diferencia entre ingresos y egresos de los condenados que el sistema penitenciario debió soportar ascendió a la cantidad de 28.600 personas que no fueron devueltas al medio libre. Estas cifras denotan que existe una parte importante de personas que progresivamente van quedando adentro de los recintos penitenciarios, engrosando la inflación. Esta tendencia, amén de que se pueda repetir con total seguridad en los próximos años, hace sospechar que esta disociación entre los flujos, pueda agravar aún más el problema carcelario.

Por otra parte, también se expone otra situación de extrema importancia, como es, que la prisión preventiva con la reforma procesal penal ha tenido una tendencia al alza en términos absolutos en su utilización, pero no obstante ello, el nuevo sistema es equilibrado en su manejo y es capaz de enviar al medio libre a prácticamente la misma cantidad de personas que ingresan en él. Antes de la reforma, la absorción de plazas o personas que quedaban al interior de los penales era superior al 5\% (años 1997 a 1999), lo que lógicamente producía el aumento en el stock de las personas encerradas. También la reforma vino en materia de imputados sujetos a prisión preventiva, no sólo a terminar con el largo encierro de aquellos que esperaban su sentencia en prisión, sino también a humanizar la prisión preventiva en el sentido que los imputados sujetos a esta medida cautelar, independiente de la valoración de su concesión, están permaneciendo tiempos de privación de libertad más exiguos, incluso más que muchas realidades de nuestro Derecho comparado. 
Tabla 2. Total de ingresos y egresos de condenados e imputados sujetos a prisión preventiva entre 1997-200919

\begin{tabular}{|l|l|l|l|l|l|l|}
\hline & \multicolumn{3}{|c|}{ Condenados } & \multicolumn{3}{c|}{ Procesados/Imputados } \\
\hline Año & Ingreso & Egreso & Dif. & Ingreso & Egreso & Dif. \\
\hline 1997 & 43.069 & 39.639 & 3.430 & 21.966 & 20.814 & 1.152 \\
\hline 1998 & 35.726 & 33.343 & 2.383 & 24.490 & 23.389 & 1.101 \\
\hline 1999 & 33.232 & 31.037 & 2.195 & 25.946 & 24.917 & 1.029 \\
\hline 2000 & 35.446 & 33.785 & 1.661 & 28.664 & 31.573 & -2.909 \\
\hline 2001 & 32.441 & 33.000 & -559 & 27.607 & 28.772 & -1.165 \\
\hline 2002 & 22.465 & 22.368 & 97 & 28.325 & 28.695 & 370 \\
\hline 2003 & 27.807 & 26.175 & 1.632 & 28.873 & 31.426 & -2.553 \\
\hline 2004 & 36.194 & 34.644 & 1.550 & 30.591 & 31.250 & -659 \\
\hline 2005 & 40.180 & 39.677 & 503 & 29.190 & 31.300 & -2.110 \\
\hline 2006 & 44.398 & 39.255 & 5.143 & 32.631 & 34.180 & -1.549 \\
\hline 2007 & 36.547 & 31.837 & 4.710 & 37.392 & 37.142 & 250 \\
\hline 2008 & 44.314 & 40.555 & 3.759 & 39.097 & 38.559 & 538 \\
\hline 2009 & 42.706 & 40.610 & 2.096 & 36.825 & 36.021 & 804 \\
\hline Total & 474.525 & 445.925 & 28.600 & 391.597 & 398.038 & -5.701 \\
\hline
\end{tabular}

Fuente. Elaboración propia a partir de los datos del Gendarmería de Chile (Compendio Estadístico).

Para finalizar, debemos indicar que la producción de este factor se sustentaría probablemente en la incidencia de la reforma procesal penal y en la presencia de algunas leyes favorecedoras de la prisionización.

\section{La incidencia de la reforma procesal penal}

En diciembre del año 2000, se dio inicio a la puesta en marcha de un nuevo sistema de administración de justicia penal en Chile que reemplazó por completo al que existió en nuestro país desde el siglo pasado, contenido en el reconocido Código de Procedimiento Penal, originario del año 1906.

\footnotetext{
${ }^{19}$ Estos resultados hay que observarlos con cierto recelo, puesto que los ingresados y egresados aquí señalados, dicen relación con el número total de movimientos que ocurren dentro del sistema penitenciario, que involucra a los procesados/imputados y condenados (los condenados con Salida Controlada al Medio Libre y los condenados recluidos en CET) del sistema cerrado penitenciario. Los "ingresados" a las calidades de procesados o imputados y condenados en un porcentaje muy alto corresponden a cambios en la calidad penal de los internos que se encuentran bajo una condición procesal determinada previamente. Lo mismo ocurre en el caso de los "egresados" dentro del sistema, por las condiciones de cambio de situación que se dan más o menos en los mismos términos.
} 
La reforma procesal penal en Chile, se estatuye mediante ley $N^{\circ} 19.696$, también reconocida como el nuevo Código Procesal Penal, publicado el 12 de octubre de 2000, que sustituye el antiguo sistema inquisitivo (en el que el juez penal cumple una triple función: conduce la investigación, acusa y sentencia) por un sistema acusatorio (existe una separación de roles: el juez, se limita a dictar la sentencia; el fiscal, conduce la investigación y acusa en interés de la sociedad). Esta denominada nueva justicia, donde cambia el paradigma imperante por cerca de un siglo, persigue como fines generales: alcanzar una administración de justicia penal mucho más rápida; los acusados y víctimas de delitos cuentan con derechos explícitos; superar los problemas estructurales que tenía el sistema inquisitivo con respecto a las garantías básicas de las personas perseguidas penalmente, ${ }^{20}$ y la existencia de un órgano constitucional autónomo e independiente que investigue la existencia de hechos revestidos del carácter de delito y establezca sus responsables.

Dicho lo anterior a título introductorio, corresponde hacerse cargo en establecer de qué manera la reforma procesal penal ha incidido en las elevadas cifras de personas encarceladas que se registran en esta década en los distintos centros penitenciarios del país. En ese sentido, nuestra opinión está conteste con la opinión mayoritaria, en orden a afirmar que la reforma efectivamente ha impactado en el aumento de la población recluida en las cárceles chilenas, ${ }^{21}$ pero nuestro análisis difiere de que éste sea la única causa que ha producido este fenómeno y de qué manera ésta influyó en su ocurrencia. Creemos que la reforma sólo aceleró una tendencia que ya nuestro país presentaba con antelación. Dicho de otro modo, la reforma ha ayudado a advertir con rapidez la necesidad de que se requieren más cárceles. Sin la modificación legal, la respuesta hubiese sido exactamente la misma, dado que como advertimos supra, ${ }^{22}$ existen causas endémicas asociadas al incremento de la población penal.

Ahora bien, en lo que respecta a la forma en cómo la reforma procesal penal ha contribuido al crecimiento sistemático de las personas que se encuentra privadas de libertad, debemos indicar que etiológicamente esto pudiese res-

\footnotetext{
${ }^{20}$ Véase RieGo, Cristian, "El Proceso Penal Chileno y los Derechos Humanos", Cuadernos de Análisis Jurídico, volumen I, número 4, Serie Especial (1994), Facultad de Derecho de la Universidad Diego Portales, p. 166.

${ }^{21}$ Véase Álvarez Tuza, Pablo; Marangunic Hinojosa, Antonio; Herrera Bilbao, Raúl, "Impacto de la reforma procesal penal en la población carcelaria del país", Revista de Estudios Criminológicos y penitenciarias 11 (2007), pp. 117-132. También, CASTILLO VAL, Ignacio, La cárcel y la política criminal, Texto inédito, que su autor facilitó y autorizó citar; Consejo para la reforma penitenciaria. Recomendaciones para una nueva política penitenciaria. Santiago, marzo, 2010, p.23. En: http://www.pazciudadana.cl/docs/ pub_20100319142517.pdf [visitado el 22/10/10].
}

22 Supra. pp. 2 y ss. 
ponder a lo que hemos denominado como una nueva estructura orgánica en el control del delito y de la justicia penal, y a lo que se conoce como nuevos procedimientos funcionales de autoincriminación.

\section{i. Estructura orgánica de las organizaciones encargadas del control del delito y de la justicia penal}

Las organizaciones son sistemas diseñados para alcanzar metas y objetivos por medio de los recursos humanos y de otro tipo. En el caso particular de la implementación de la reforma procesal penal, se originan nuevos agentes encargados del control y de la justicia penal, se crea una nueva organización, denominada Ministerio Público, el cual es un organismo autónomo, cuya función es dirigir de manera exclusiva la investigación de los delitos, llevar a los imputados a los tribunales, si corresponde, y dar protección a víctimas y testigos. Además, se modifica totalmente la estructura orgánica de los tribunales encargados de impartir justicia penal, desaparecen paulatinamente los antiguos Juzgados del Crimen y son reemplazados por los Tribunales de Garantía y los Tribunales Orales en lo Penal. ${ }^{23}$

La forma de cómo estas dos organizaciones -Ministerio Público y Poder Judicial-, que orgánica y funcionalmente son distintas entre sí, pero que participan en común de ciertas características que han contribuido al incremento de la población penitenciaria -situación que el antiguo sistema o proceso penal no lo permitía- puede ser reducido en general a la organización y gestión o en general al management que la reforma ha ofrecido en el sistema de justicia penal. Ésta ha permitido, entre otras cosas, una mejora cuantitativa y cualitativa de los términos de los procesos penales -judicializados y no judicializados-, un aumento en la tasa de condenas y una notable reducción en los tiempos de duración de los procesos judiciales.

a) Incremento cuantitativo y cualitativo en los ingresos y términos de los procesos judiciales: según cifras entregadas por Carabineros y la Policía de Investigaciones de Chile, en el año 2001, el total absoluto de denuncias registradas en estos organismos ascendió a 1.628 .775 casos. $^{24}$ Para ese mismo período, conforme las estadísticas del Ministerio de Justicia, el total de sentencias condenatorias y absolutorias alcanzó un total de 39.671 casos. ${ }^{25}$ Con estas cifras,

\footnotetext{
${ }^{23}$ Actualmente existen 625 fiscales y 816 jueces (antes de la reforma sólo habían 70 jueces especializados) dedicados a este nuevo sistema de justicia. Estas cifras aparecen de la entrevista a Iván Fuenzalida, Director Unidad de Estudios del Ministerio Público. En prensa.

${ }^{24}$ Véase Anuario Estadísticas Carabineros de Chile y Policía de Investigaciones de Chile. En: www.ine. cl [visitado el 22/11/10].

${ }^{25}$ Véase Anuario Ministerio de Justicia año 2001. En: www.ine.cl [visitado el 22/1110].
} 
las cuales no son casuales dado que se repiten los años anteriores, ${ }^{26}$ podemos advertir que si bien existía un alto ingreso de denuncias, respecto de las cuales desconocemos cuántas de ellas eran efectivamente judicializadas, los términos que se procuraban vía sentencia condenatoria o absolutoria, no superaba el 2,4 $\%$ del total de ingresos en el año respectivo. ${ }^{27}$

Lejos de estos resultados del sistema antiguo que pudiesen ser calificados de magros, la Tabla 3 deja de manifiesto lo que se produce con la entrada en vigencia de la reforma procesal penal. Los ingresos vía denuncia, querella o pesquisa de oficio, experimentan un aumento constante en cada uno de los intervalos de la década y, a partir del año 2006 donde la reforma está completamente interiorizada en todas las regiones del país, los términos a través de una salida judicial, ${ }^{28}$ no judicia ${ }^{29}$ y los denominados por el Ministerio Público otros términos ${ }^{30}$ superan el total de ingresos de esos años. Si bien esto no lo podemos calificar de eficiencia -utilización de menos recursos para lograr objetivo, o, al contrario, cuando se logran más objetivos con los mismos o menos recursos- ya que se requiere de un examen cualitativo mayor para conocer si se alcanza el efecto de una mayor y mejor persecución penal, es probable que podamos catalogarlo de resultados eficaces -podemos definirla como el nivel de consecución de metas y objetivos-, donde se ha logrado como objetivo alcanzar una administración de justicia penal acelerada. ${ }^{31}$ A modo de ejemplo, en el año 2009 el total de términos es superior en un $8 \%$ al total de ingresos de ese mismo período. Con esto, no estamos señalando que el total de casos ingresados se terminó con un superávit ese mismo año, sino que $-y$ sin perjuicio de que ello pudiese efectivamente suceder- el fenómeno que se presenta, es que la justicia de manera cierta está dando una respuesta -independiente de su valorización en términos de positiva o negativa- fluida y acelerada a la demanda de los ciudadanos. Respuesta que el sistema procesal antiguo no era capaz de entregar por problemas asociados, seguramente, a la gestión en el tratamiento de los distintos procesos judiciales.

\footnotetext{
${ }^{26}$ Véase Anuario Estadísticas Carabineros de Chile, Policía de Investigaciones de Chile, Ministerio de Justicia. En: www.ine.cl [visitado el 22/11/10].

${ }^{27}$ No se consideran los sobreseimientos definitivos y temporales, conforme a los artículos 408 y 409 del Código de Procedimiento Penal.

${ }^{28}$ La salida judicial considera: acuerdo reparatorio, facultad de no investigar, sentencia definitiva condenatoria, sentencia definitiva absolutoria, sobreseimiento definitivo, sobreseimiento temporal y suspensión condicional del procedimiento.

${ }^{29}$ La salida no judicial considera: archivo provisional, decisión de no perseverar, incompetencia y principio de oportunidad.

${ }^{30}$ El Ministerio Público entiende por "otros términos" las siguientes formas de término: agrupación a otro caso, anulación administrativa, otras causales de suspensión y otras causales de término.

${ }^{31}$ Véase exposición de motivos del Código Procesal Penal.
} 
Tabla 3. Total de ingresos, total de términos, términos judiciales en Ministerio Público entre 2000-2009

\begin{tabular}{|l|l|l|l|}
\hline Año & Ingresos & Términos & Términos Judiciales \\
\hline 2000 & 1.308 & 114 & 10 \\
\hline 2001 & 99.655 & 79.483 & 12.785 \\
\hline 2002 & 170.319 & 188.333 & 23.944 \\
\hline 2003 & 234.677 & 240.079 & 39.687 \\
\hline 2004 & 516.405 & 504.127 & 96.879 \\
\hline 2005 & 757.428 & 638.960 & 175.870 \\
\hline 2006 & 969.302 & 909.236 & 321.058 \\
\hline 2007 & 1.110 .298 & 1.048 .571 & 394.230 \\
\hline 2008 & 1.255 .397 & 1.295 .699 & 534.375 \\
\hline 2009 & 1.312 .362 & 1.422 .755 & 666.394 \\
\hline
\end{tabular}

Fuente. Elaboración propia a partir de los datos del Ministerio Público. En Estadísticas del Ministerio Público.

Por último, como se desprende en la tabla, es necesario destacar que las salidas judiciales que el sistema otorga a partir del año 2006 hasta el 2009, ha ido progresivamente incrementándose y equivale en promedio al $41 \%$ de los casos ingresados en cada uno de esos años. Esto pudiese denotar que la respuesta judicializada como reacción al delito va en franco aumento en términos absolutos y que la posibilidad de una sentencia condenatoria como premisa para la prisión corre la misma suerte.

b) Aumento en la tasa de condenas: como se dijo anteriormente, si bien la Reforma Procesal Penal aumentó los términos judiciales, esto no implica per se un alza de la población penal. El único factor que, analizado bajo el epígrafe de la incidencia de la Reforma Procesal Penal, tiene un impacto directo en el aumento de la población penal, es el incremento de la tasa de condenas.

Cuando nos referimos a "condena", estamos haciendo alusión a la existencia de una sentencia que impone al acusado de un delito una pena de multa o una pena privativa de libertad, independiente de que respecto esta última esté o no suspendido su cumplimiento efectivo, por operar en su favor alguno de los beneficios previstos en la ley $N^{\circ} 18.216$.

Las condenas en Chile, en términos absolutos y relativos, reflejan una variación positiva constante. Como se puede advertir en la Tabla 4, entre los años 1998 y 1999, ocaso del sistema inquisitivo, las tasa de condena era de 194 y 226 personas condenados respectivamente por cada cien mil. Entrada la reforma, y a partir del año 2006 la tasa de condena presenta un incremento sin parangón. Ese año, anota una tasa de 740 personas, para posteriormente seguir 
en aumento y llegar en el año 2009 a una tasa histórica de 1.467 personas por cada cien mil.

La probable razón de este constante aumento puede encontrarse en el incremento que ha generado la Reforma Procesal Penal en la denominada probabilidad de condena, la cual se calcula como el cociente entre la tasa de condena del delito específico en un tiempo $t$ y la tasa de denuncia para el mismo delito en un tiempo t-1. Así, por ejemplo, en el periodo 1998-2006 en lo que respecta al delito de robo con fuerza, el indicador porcentual no supera en promedio el 3,5\%, lo que comunica que la probabilidad de que un delincuente sea condenado por este ilícito no supera ese tanto por ciento. ${ }^{32}$ En el año 2009, la cosa cambió, la probabilidad de condena para ese mismo delito prácticamente se duplicó, fue de $6,5 \% .^{33}$

\section{Tabla 4. Total sentencias condenatorias en términos absolutos y relativos entre los años 1998-2009}

\begin{tabular}{|l|c|c|}
\hline Año & Sentencias Condenatorias & Tasa de Condenas \\
\hline 1998 & 29.093 & 194 \\
\hline 1999 & 34.836 & 226 \\
\hline \multicolumn{2}{|c|}{ Reforma Procesal Penal } \\
\hline 2000 & 8 & 0 \\
\hline 2001 & 11.062 & 71 \\
\hline 2002 & 13.989 & 89 \\
\hline 2003 & 19.048 & 120 \\
\hline 2004 & 45.383 & 282 \\
\hline 2005 & 73.202 & 450 \\
\hline 2006 & 121.580 & 740 \\
\hline 2007 & 163.872 & 988 \\
\hline 2008 & 215.914 & 1.288 \\
\hline 2009 & 248.140 & 1.467 \\
\hline
\end{tabular}

Fuente. Elaboración propia a partir de los datos publicados en el Ministerio Público y el Ministerio de Justicia.

32 Salinero, Sebastián, "Incidencia de la Probabilidad de Condena en los Delitos de Robo. Análisis Descriptivo y Comparado", en Política Criminal 8 (2009), pp. 430-474, p. 39. En: http://www.politicacriminal.cl/Vol_04/n_08/Vol4N8A5.pdf [visitado el 22/11/10].

${ }_{33}$ Cálculo propio según datos del Ministerio Público, Anuario 2009. En: www.ministeriopublico.cl [visitado el 20/05/11]. 
Si bien la tasa de condena ha experimentado un incremento sin parangón. Para los fines de este estudio, lo que debemos establecer es qué cantidad de esas condenas impusieron penas privativas de libertad sin beneficios de la ley $N^{\circ} 18.216$, o sea, sentencias que ordenaron el cumplimiento efectivo de la pena en un centro carcelario. Para tales efectos, de manera de poder realizar un análisis comparado entre lo sucedido a contar de la plenitud de vigencia de la reforma y antes de ella, recurriremos a las estadísticas del Ministerio de Justicia entre los años 1998-2000, y las estadísticas de la Defensoría Penal Pública, específicamente a los datos registrados en torno a la Región Metropolitana entre los años 2005-2009. Previamente, debemos señalar que antes de la reforma, sobre este punto, las estadísticas que existían eran sólo las publicadas por el Ministerio de Justicia, las cuales tenía desde el punto vista espacial carácter nacional, de manera que no se podía acceder a información parcializada o desagregada para cada región. A partir de la reforma, no hay información pública al respecto, los datos que tenemos son obtenidos del sistema de seguimientos de causas de la Defensoría Penal Pública (SIGDP), del cual no podemos obtener resultados a nivel nacional ya que no considera el total de procesos penales involucrados -no todos los imputados son defendidos por este organismo público- y al no tener el carácter de información oficial sus resultados deben ser mirados con cierto recelo, pero no por ello restarles absoluto valor.

Dicho lo anterior, podemos decir que, como se refleja en la Tabla 5, antes de la reforma, esto es, entre los años 1998-2000, en todo el país la tasa de condenados a penas de prisión efectiva fue de 95 personas por cada cien mil. A su vez, la Región Metropolitana con poco más de la tercera parte de la población total de Chile, registró a partir del año 2005 e inicio de la reforma una variación positiva superior al $260 \%$, dando lugar a una tasa en el año 2009 de 81 personas por cada cien mil condenados a una pena efectiva.

También otros estudios respaldan esta tendencia. Por ejemplo, en Álvarez, Marangunic y Herrera, se estableció que las sentencias condenatorias experimentaron un alza sostenida a partir del año 2002. Al complementar esas cifras con la evolución temporal de los condenados a penas efectivas en los últimos 18 meses (enero 2006-junio 2007), se pudo observar un claro aumento del segmento de condenados que debió cumplir su sentencia en recintos carcelarios, Ilegando a un total de 34.210 personas en un rango de tiempo de un año y medio. En términos promedio, el estudio concluyó que, durante el período analizado, ingresaron mensualmente a las cárceles chilenas un número cercano a las 1.890 personas. ${ }^{34}$

34 Álvarez; Marangunic; Herrera, "Impacto", cit. nota n. 21, p. 124 y ss. También, Fundación Paz Ciudadana, en Recomendaciones para una nueva política penitenciaria. Santiago, marzo, 2010, pp. 124 y ss. En: http://www.pazciudadana.cl/docs/pub_20100319142517.pdf, [visitado el 20/05/11]. 


\section{Tabla 5. Total sentencias condenatorias sin beneficios en términos} absolutos y relativos entre los años 1998-2009

\begin{tabular}{|c|c|c|c|}
\hline Año & Condenados & Tasa & \\
\hline 1998 & 14.320 & 96 & \multirow{3}{*}{ Todas las Regiones } \\
\hline 1999 & 14.363 & 95 & \\
\hline 2000 & 14.648 & 95 & \\
\hline \multicolumn{3}{|c|}{ Reforma Procesal Penal } & \\
\hline 2005 & 3.616 & 22 & \multirow{5}{*}{$\begin{array}{l}\text { Región } \\
\text { Metropolitana }\end{array}$} \\
\hline 2006 & 6.423 & 39 & \\
\hline 2007 & 9.070 & 55 & \\
\hline 2008 & 11.282 & 67 & \\
\hline 2009 & 13.647 & 81 & \\
\hline
\end{tabular}

Fuente. Elaboración propia a partir de los datos publicados en el Instituto Nacional de Estadísticas y Ministerio Público.

c) Reducción en los tiempos de duración de los procesos judiciales: este debe ser uno de los puntos donde la reforma ha calado mayormente. Empíricamente el discurso que la nueva justicia sería más rápida en el tratamiento de las investigaciones y procesos judiciales dejó de ser una utopía para transformarse de manera efectiva, según advierten las cifras, en una realidad.

Para demostrar el cambio, debemos recurrir a las cifras del sistema antiguo. Para ello, la Tabla 6 muestra los resultados entre los años 1998 y 2001, en los cuales, en promedio, el $51 \%$ de los procesos judiciales tuvo una duración entre 6 meses y 2 años; luego, sólo el 31\% duró menos de 6 meses; el 15\% demoró entre los 2 y 5 años; y, finalmente, el 3\% tuvo un tiempo de duración superior a los 5 años.

Tabla 6. Tiempos promedios de duración de los procesos penales en el sistema procesal antiguo

\begin{tabular}{|l|l|l|l|l|}
\hline Año & $0-6$ meses & 6 meses -2 años & $2-5$ años & Más 5 años \\
\hline 1998 & 9.459 & 16.935 & 4.875 & 1.048 \\
\hline 1999 & 10.957 & 17.548 & 5.235 & 1.096 \\
\hline 2000 & 12.187 & 17.852 & 5.036 & 1.300 \\
\hline 2001 & 10.302 & 18.263 & 4.765 & 1.143 \\
\hline
\end{tabular}

Fuente. Elaboración propia a partir de los datos publicados en los Anuarios de Justicia. En Instituto Nacional de Estadísticas (INE). 
La reforma procesal penal pone término al dilatado tiempo de demora de los procesos criminales. De acuerdo a la Tabla 7, en la presente década el promedio de duración de un proceso penal no es superior a 2 meses (61 días). A contar del segundo lustro, el cual pudiese aportar datos más cercanos a la realidad por entenderse que estaría completado el proceso de interiorización y ejecución de la reforma en todo el país, el promedio es de 4 meses y fracción de días (total de 129 días).

Tabla 7. Tiempos promedios de duración de los procesos penales en el nuevo sistema procesal penal

\begin{tabular}{|l|c|}
\hline Año & Promedio Total (Días) \\
\hline 2000 & \multirow{2}{*}{} \\
\cline { 1 - 1 } 2001 & \multirow{2}{*}{27} \\
\hline 2002 & \\
\cline { 1 - 1 } 2003 & \\
\hline 2004 & \\
\hline 2005 & \\
\hline 2006 & 119 \\
\hline 2007 & 138 \\
\hline 2008 & 132 \\
\hline 2009 & 126 \\
\hline
\end{tabular}

Fuente. Elaboración propia a partir de los datos publicados en el Ministerio Público.

Estos tiempos son mejorados según estadísticas de la Defensoría Penal Pública, en el año 2009 cerca del 46,7 \% de los procesos amparados por ese organismo público término en menos de 2 semanas; el 35,2\% duró menos de 6 meses; el $11 \%$ entre 6 meses y 1 año, y sólo el 7,2\% demoró más de 1 año. ${ }^{35}$

Esta mejora en los tiempos de duración de los procesos criminales, además de contribuir a lograr las expectativas generadas con la reforma procesal penal, posibilitan que la reacción penal ante la comisión de un delito tenga una respuesta más inmediata a la otorgada en el antiguo sistema.

\section{ii. Procedimientos funcionales de autoincriminación}

Cuando nos referimos a procedimientos de autoincriminación que inciden de manera positiva en el aumento de la población penal estamos haciendo estricta alusión a los procedimientos simplificado y abreviado respectivamente.

\footnotetext{
${ }^{35}$ Defensoría Penal Pública, Informe Anual 2009. En: www.dpp.cl [visitado el 20/05/11].
} 
Estos procedimientos implantados por la reforma procesal penal, son especiales y sumarios. Se trata de la introducción de mecanismos de celeridad y simplificación al procedimiento ordinario, el que, generalmente, es más complejo, de más etapas -constituido por tres grandes etapas: de investigación, de preparación de juicio y de juicio oral-y más laxo en su duración.

Las razones de cómo estas formas de enjuiciamiento pueden ayudar al incremento de la población carcelaria, pueden ser reducidas a dos causas: la celeridad de los procedimientos y el consenso punitivo permitido.

Tanto el procedimiento simplificado, ${ }^{36}$ Como el procedimiento abreviado, ${ }^{37}$ son formas de enjuiciamiento que constituyen una forma expedita de juzgar hechos constitutivos de delito y de esta manera plasmar en forma efectiva el derecho del imputado por un delito a ser juzgado en un plazo razonable o sin dilaciones indebidas. ${ }^{38}$

Tabla 8. Evolución sentencias condenatorias y absolutorias en procedimientos simplificado y abreviado entre los años 2000-2009

\begin{tabular}{|l|c|c|c|c|}
\hline Año & $\begin{array}{c}\text { Condena } \\
\text { Simplificado }\end{array}$ & $\begin{array}{c}\text { Absolución } \\
\text { Simplificado }\end{array}$ & $\begin{array}{c}\text { Condena } \\
\text { Abreviado }\end{array}$ & $\begin{array}{c}\text { Absolución } \\
\text { Abreviado }\end{array}$ \\
\hline 2000 & \multicolumn{5}{|c|}{ no hay información } \\
\hline 2001 & 601 & 29 & 166 & 4 \\
\hline 2002 & 1.300 & 59 & 1.044 & 6 \\
\hline 2003 & 3.005 & 61 & 1.931 & 65 \\
\hline 2004 & 12.786 & 226 & 4.797 & 123 \\
\hline 2005 & 27.129 & 435 & 9.217 & 279 \\
\hline 2006 & 41.487 & 559 & 19.148 & 220 \\
\hline 2007 & 52.317 & 840 & 24.569 & 34.035 \\
\hline 2008 & 68.156 & 998 & no hay información \\
\hline 2009 & & \multicolumn{5}{|c|}{} \\
\hline
\end{tabular}

Fuente. Elaboración propia a partir de los datos publicados en el Ministerio Público.

\footnotetext{
${ }^{36}$ Procedimiento especial que se aplica a faltas o simples delitos en que el Ministerio Público requiere la imposición de una pena en concreto que no exceda de presidio o reclusión menor en su grado mínimo (540 días). Se regula en los artículos 388 y ss. del Código Procesal Penal.

37 Procedimiento especial que se aplica a crímenes o simples delitos en que el Ministerio Público requiere la imposición de una pena en concreto que no exceda de presidio o reclusión menor en su grado máximo (5 años). Se regula en los artículos 406 y ss. del Código Procesal Penal.

${ }^{38}$ Sobre los alcances de este derecho, véase Horvitz Lennon, María Inés; LóPEz MASLE, Julián, Derecho Procesal Penal Chileno, T. I, Editorial Jurídica de Chile, Santiago, 2005, p. 72.
} 
Estos procedimientos no ajenos de críticas en doctrina, ${ }^{39}$ permiten, en general, imponer al imputado de un delito, una pena inferior, siempre y cuando, éste acepte responsabilidad (procedimiento simplificado) o acepte los hechos de la acusación y antecedentes de la investigación del persecutor penal (procedimiento abreviado). Sin entrar a un análisis profundizado sobre cada uno de estos procedimientos, para los efectos de este trabajo podemos señalar que en ellos existe, a lo menos desde el punto de vista práctico, una suerte de negociación previa (consenso) de la pena entre el Ministerio Público y el imputado, donde este último es beneficiado con una pena menor, y el primero con un importante ahorro de tiempo y recursos en probar su pretensión penal en el respectivo juicio oral.

Estos procedimientos, basados en la autoincriminación, han tenido un incremento sostenido, favoreciendo la imposición rápida y negociada de una pena, que en una gran cantidad de casos será de cumplimiento efectivo; permiten no sólo inferir que colaboran estrechamente con las elevadas y actuales cifras de inflación penitenciaria, sino que también inciden en la punición efectiva de la eventual segunda condena (Reincidencia). En efecto, años pasados, la persona que cometía un delito y era favorecida con un beneficio alternativo a la prisión, y posteriormente cometía un nuevo delito, podía demorar en recibir la segunda condena que eventualmente trae aparejada una pena de prisión efectiva entre 2 y 5 años. En cambio, las condiciones actuales de estos procedimientos, permiten inferir que para el mismo caso la persona reciba la segunda condena antes de que transcurran 6 meses contados desde el primer hecho.

A nuestro entender, el incremento de las condenas en estos procedimientos fue mayor cuando entró en vigencia la ley $\mathrm{N}^{\circ} 20.074,{ }^{40}$ de 14 de noviembre de 2005, que incorporó una serie de modificaciones al Código Procesal Penal y otros cuerpos legales, con la idea de perfeccionar el nuevo sistema de investigación y enjuiciamiento penal. La finalidad perseguida con esta ley, no fue otra que, con la experiencia de la reforma en Regiones -antes de llegar a la Metropolitana-, agilizar la persecución penal, evitando zonas de impunidad, y corregir los errores normativos de los procedimientos de autoincriminación que se había detectado en las etapas de implementación.

\footnotetext{
${ }^{39}$ Para un panorama general sobre la cuestión, véase Horvitz; LóPEZ, Derecho, cit. nota n. 38, pp. 461, pp. 510 y ss.

${ }^{40}$ CASTILlo VAL, Ignacio, La cárcel, cit. nota n. 21. Entiende que la ley $N^{\circ} 20.074$ entre otras cosas, tuvo por objeto "evitar zonas de impunidad en la persecución penal", lo que el ejecutivo tradujo en rebajar los estándares para la aplicación de la prisión preventiva; aumentar el número de condenas incentivando los mecanismos de autoincriminación mediante la negociación de penas más bajas, y modificar las normas del procedimiento simplificado para que se pudiera condenar a penas de simple delitos y no sólo de prisión o multa.
} 
Para determinar el impacto de la ley $\mathrm{N}^{\circ} 20.074$ en el crecimiento de los procedimientos de autoincriminación, al margen del sesgo que podía significar que la Reforma Procesal penal entró en vigencia en la Región Metropolitana el mismo año de la ley en comento, proponemos realizar un análisis comparativo antes y después de la entrada en vigencia de la ley $N^{\circ} 20.074$, en aquellas zonas que la reforma procesal ya llevaba operando desde su inicio (IV y IX Región). Así las cosas, en el año 2004 -antes de la ley No 20.074-, en la IV y IX Región, el total de condenados en procedimiento simplificado fue de 1.374 y 929 personas respectivamente. En cambio, en el año 2006 -en vigencia la ley $N^{\circ} 20.074$ el número de condenado aumentó. Mientras en la IV Región los condenados en estos procedimientos fue de 7.868 personas, en la IX región fue de 7.298. En relación al procedimiento abreviado, la situación fue igual. Antes de la ley $N^{\circ} 20.074$, en la IV Región el total de condenados ascendió a 538 personas y en la IX Región fue de 992. Por su parte, con ley № 20.074, las cifras también se elevaron, en la IV Región los condenados fueron 2.638 personas y en la IX Región de 4.365 personas. ${ }^{41}$

Conforme la Tabla 8, el alza en las condenas que representan estos procedimientos ha sido exponencial. Las condenas que arroja el procedimiento simplificado desde el año 2001 al 2008, ha crecido en una cifra superior al $11.000 \%$. Para el mismo período, el procedimiento abreviado no se queda atrás, y su crecimiento supera el $20.000 \%$. Estas cifras, no sólo dan cuenta del incremento en la utilización de estos procedimientos, sino también de la posibilidad racional que por ellos crezca la población penal.

\section{Leyes que favorecen la prisionización}

Bajo este epígrafe nos hemos querido referir a algunas leyes que tiene un alto impacto en el favorecimiento de ingresos de personas al sistema carcelario. Esta tendencia a la prisionización denota, por una parte, una política criminal de "tolerancia cero" que impera en nuestra sociedad y, por otra, el carácter que tiene la prisión como única respuesta penal.

Podrían ser manifestación de este fenómeno, la sustitución por la prisión de la pena de multa impaga y los denominados delitos dentro del contexto de la violencia intrafamiliar.

\section{i. La multa impaga}

La trascendencia que ha adquirido hoy la multa impaga con la reforma procesal penal y como ella ha servido para procurar la inflación penitenciaria

\footnotetext{
${ }^{41}$ Véase Boletín Estadístico del Ministerio Público, correspondiente a los años 2004 y 2006.
} 
es un fenómeno que, creemos, no ha sido revelado en la dimensión que realmente tiene.

El Código Penal, en su artículo 49 regula la situación de la multa impaga, prescribiendo la sustitución de aquella por la pena de reclusión en caso que ésta no sea satisfecha por el penado. Hasta antes de la reforma procesal, el artículo 563 del antiguo Código de procedimiento penal contemplaba la posibilidad de sustituir la multa impaga por la reclusión nocturna del infractor. Esta norma, que no es originaria de ese Código de enjuiciamiento, vino el año 1997, ${ }^{42}$ a paliar un problema que hasta esa fecha existía y que se extrapolaba a la actualidad, y no era otro, que la gran cantidad de personas que se encontraban cumpliendo penas privativas de libertada como consecuencia del impago de la multas. Sin embargo, con la entrada en vigencia de la reforma procesal penal, el año 2000, y posteriormente en la Región Metropolitana, el año 2005, la posibilidad de sustituir las multas impagas por la reclusión nocturna desapareció con el subsecuente incremento de la población penal.

Es tal la incidencia que ha ocasionado la multa impaga en la inflación penitenciaria, que en el año 2009 el porcentaje de ella sobre el total de la población penal, alcanzó algo más del 9\%. El incremento en términos absolutos es categórico y progresivamente positivo para cada año, mientras el año 2003 ostentaba un índice cercano al 6\%, en los comienzos de la primera década de este siglo ni siquiera llegaba al $1 \%{ }^{43}$

\section{ii. Violencia intrafamiliar}

Este concepto compuesto, alberga una serie de delitos que son constitutivos de un maltrato que afecta la vida o la integridad física o psíquica de la víctima, y que proviene y se desarrolla en contra de ciertas y determinadas personas que la ley individualiza. ${ }^{44}$ Dada la amplitud de delitos que se puede recoger bajo esta consigna, no es si no, con la práctica del foro judicial que los delitos

\footnotetext{
${ }^{42}$ Por ley $\mathrm{N}^{\circ} 19.501$, de mayo de 1997, Por su parte, la Ley $\mathrm{N}^{\circ} 18.287$ sobre Procedimiento ante los Juzgados de Policía Local, regula aún, en su artículo 23, la posibilidad de sustituir en forma total o parcial la multa impaga por la reclusión nocturna, reclusión diurna o reclusión de fin de semana.

43 Índices de elaboración propia, en base a la información obtenida desde los Compendios de Gendarmería de Chile, correspondiente a los años 2001, 2003 y 2009.

${ }^{44}$ Art. $5^{\circ}$ de la ley $N^{\circ}$ 20.066: “(...) quien tenga o haya tenido la calidad de cónyuge del ofensor o una relación de convivencia con él; o sea pariente por consanguinidad o por afinidad en toda la línea recta o en la colateral hasta el tercer grado inclusive, del ofensor o de su cónyuge o de su actual conviviente. También habrá violencia intrafamiliar cuando la conducta referida en el inciso precedente ocurra entre los padres de un hijo común, o recaiga sobre persona menor de edad, adulto mayor o discapacitada que se encuentre bajo el cuidado o dependencia de cualquiera de los integrantes del grupo familiar".
} 
envueltos bajo este título han quedado relativamente determinados y estarían dados en general por las lesiones (en todo su espectro punitivo), delitos contra la libertad e intimidad de las personas y homicidios.

Estos delitos, en el contexto de la violencia intrafamiliar, han tenido un importante incremento en su denuncia. Mientras el año 2007 ingresaban algo más de 56 mil denuncias, el año 2010 esta cifra se duplicó a casi 123 mil (Fuente Estadísticas Ministerio Público).

El impacto de estos delitos en la población penal puede medirse desde tres esferas. La primera, es aquella que dice relación con el número de individuos que ha sido condenado por estos delitos, donde a modo meramente ejemplar podemos decir que el año 2007, en términos absolutos, se dictó un total nacional de 5.079 sentencias condenatorias, mientras el año 2010, esta cifra casi se triplicó, alcanzando un total de 14.257 sentencias condenatorias (Fuente Estadísticas Ministerio Público). La segunda esfera, es la que dice relación con la cantidad de imputados formalizados por estos delitos y respecto de los cuales se solicitó y se concedió la prisión preventiva como medida cautelar. En este punto, podemos señalar que con la escueta información de que disponemos, entre los años 2009 y 2010, el total de privados de libertad sujetos a esta medida cautelar llegó a algo más de 1.000 personas. ${ }^{45}$ Por último, la tercera esfera, la cual sería más propia del factor que se desarrollará en el título siguiente, a propósito de la mayor permanencia de los penados en prisión, pero por razones equemáticas hemos decidido tratarla en el presete epígrafe, dice relación con el endurecimiento de las penas y restricción de ciertos derechos que rodea el sistema de los delitos que sanciona la violencia intrafamiliar. En efecto, el delito de lesiones -que dicho sea de paso es el ilícito más característico de la violencia intrafamiliar-a partir de octubre de 2005, es sancionado con una pena superior en un grado al que establece el marco penal para el delito respectivo en abstracto. ${ }^{46}$ Por ejemplo, si nos encontramos frente a las tradicionales lesiones leves que tienen asignado en la ley una pena de multa, pero si éstas son cometidas cotra las personas que protege la Ley de Violencia Intrafamiliar, serán castigados lisa y llanamente como autores de lesiones menos graves, con una pena que va desde los 61 a los 540 días de prisión. Además, esta misma ley restinge ciertos derechos a los imputados por los delitos de la violencia intrafamiliar, tales como,

\footnotetext{
${ }^{45}$ La información de sujetos a prisión preventiva en casos de violencia intrafamiliar no se encuentra desagregada de la información total de sujetos en prisión preventiva. Estas cifras las obtuvimos de los Anexos de Causas de Violencia Intrafamiliar (VIF), en las Estadísticas de la Defensoría Penal Pública. Para el año 2009 el total de privados de libertad fue de 568 personas y el año 2010 fue de 471 personas.

${ }^{46}$ La Ley N ${ }^{\circ} 20.066$, de octubre de 2005, sobre Violencia Intrafamiliar, aumenta en un grado la pena en los delitos de lesiones cometidos contra a alguna de las personas designadas en el artículo $5^{\circ}$ de esa ley. Véase además el artículo 400 del Código Penal.
} 
la imposibilidad de acceder a la salida alternativa de acuerdo reparatorio. ${ }^{47}$ Esta última medida, como la anterior, propician innegablemente la prisionización en esta clase de delitos.

VII. SEGUNDO FACTOR: LA MAYOR PERMANENCIA EN PRISIÓN DE LAS PERSONAS INGRESADAS AL SISTEMA PENAL

El segundo factor que estimamos concurrente en la inflación carcelaria estaría dado por el mayor tiempo de privación de libertad que deben sufragar algunas personas.

Sería un reflejo de esta situación, el hecho ya advertido supra, los egresos de prisión frente a los ingresos han bajado bruscamente. Así, por ejemplo, el sistema carcelario en los últimos diez años, deducido los egresos frente a los ingresos, ha debido absorber una demanda de plazas ascendente a 28.600 personas condenadas. O sea, cada año existe un número importante de sujetos que van quedando permanentemente dentro de los recintos penales y que no son liberados por el flujo carcelario. Lo singular de esta situación, es que este fenómeno sólo se produce respecto de las personas que son condenadas (rematados) y no de aquellos sujetos que ingresan a los penales en virtud de una medida cautelar de prisión preventiva, donde el flujo permite liberar plazas carcelarias rápidamente. Es prueba de aquello, el hecho que en los últimos diez años existe un superávit de egresos de las personas en prisión preventiva o procesadas del antiguo sistema procesal penal (Véase Tabla 2).

Otro elemento que nos ayudaría a confirmar la situación de que algunas personas estarían sometidas a un régimen más severo de privación de libertad, en el que deben permanecer más tiempo en prisión, sería de índole cualitativo y se traduce en concreto en que algunos delitos han sufrido severas modificaciones tendientes a la agravación de sus penas o a la restricción impuesta a los condenados para acceder a los beneficios alternativos a la privación de libertad.

Esta mayor severidad, en términos generales, descansaría en lo que se conoce como punitivismo penal, el cual puede ser definido como el paradigma conforme al cual la función punitiva del Estado se configura como un instrumento "de mano dura" o de "tolerancia cero" para combatir el flagelo de la delincuencia. Este punitivismo pone término al principio clásico del Derecho penal conforme al cual el poder punitivo del Estado es reconocido como ultima ratio para intervenir y resolver los conflictos de la vida social, de modo que se entiende al Derecho penal como una herramienta funcional a la cual debe acudirse como prima ratio para la resolución de los problemas de la comunidad.

${ }^{47}$ Véase artículo 19 de la ley № 20.066. 
El punitivismo penal no es más que una manifestación del denominado doctrinariamente Derecho penal del enemigo, el cual consiste, en una especie de Derecho penal paralelo o bilateral que se distinguiría del Derecho penal clásico en que se adelantarían las barreras de punibilidad a momentos previos a la lesión del bien jurídico; se privilegian los tipos penales de peligro -sea concreto o abstracto- por sobre los de lesión, de manera que se basa no en la afectación del bien jurídico en concreto, sino en la posibilidad de que llegue a ser afectado, lo que genera enormes dudas frente a la seguridad jurídica y la certidumbre de las normas jurídico-penales; permitiría la flexibilización o restricción de garantías fundamentales para el enjuiciamiento de las personas; asignaría penas particularmente altas, sin la debida proporcionalidad que ha de existir entre el injusto y la pena a imponer; y, finalmente, estaría dirigido al enfrentamiento de ciertos individuos, considerados como "enemigos". ${ }^{48}$

A nuestro juicio, en la política criminal chilena, serían claras manifestaciones del punitivismo penal con un claro impacto en la inflación carcelaria los delitos de tráfico ilícito de estupefacientes y los delitos contra la propiedad, sean o no mediante apoderamiento violento o con peligro para las personas. ${ }^{49}$ Estos delitos tienen una amplia representación en la composición carcelaria chilena. ${ }^{50}$ Mientras que a fines de la década de los noventa, sólo en promedio el 8,5\% de la geografía carcelaria estaba conformada por delitos de drogas, en el último lustro en cambio, la media es de 9,8\%; la situación de los delitos contra la propiedad mantiene la misma constante, mientras a fines de la década pasada el promedio de delitos contra la propiedad sin apoderamiento violento era de un

\footnotetext{
${ }^{48}$ Para profundizar sobre este tema y por todos conocidos: Jakobs, Günther; CanCIO Melí, Manuel, Derecho penal del enemigo, $1^{\text {a }}$ Edición, Civitas, España, 2003.

${ }^{49}$ Las razones de por qué los delitos de la Ley de Drogas se enmarcan dentro de lo que se conoce como punitivismo penal, obedecen, nuestro juicio, al carácter de delincuencia trasnacional que tienen estos delitos y a los compromisos internacionales que asumió Chile en su persecución y castigo. En referencia al marco jurídico que fundamenta la acción de nuestro país en el tema, Chile es parte de la Convención Única sobre Estupefacientes de 1961; el Convenio sobre Sustancias Sicotrópicas de 1971; la Convención de Naciones Unidas contra el Tráfico llícito de Estupefacientes de 1988; la Convención de Naciones Unidas contra la Delincuencia Transnacional Organizada y la Convención de Naciones Unidas contra la Corrupción. También puede revisarse la explicación de este fenómeno, en el célebre libro: Silva SÁnchez, Jesús María, La expansión del derecho penal. Aspectos de la política criminal en las sociedades postindustriales, $2^{\text {a }}$ Edición, Civitas, España, 2001. Por su parte, el punitivismo en los delitos contra la propiedad, sólo puede ser explicado a partir de la Política Criminal y en la necesidad de rebajar la presencia de estos delitos en la actual sociedad en que vivimos.

${ }^{50}$ Un estudio de la Fundación Paz Ciudadana da cuenta que a propósito de la prisión preventiva los delitos contra la propiedad y de la Ley de Drogas tienen la mayor representación en la geografía penitenciaria de ese indicador. Para este efecto véase Morales, Ana María; Pérez, Pablo; WelsCh, Gherman, "Caracterización de la población en prisión preventiva", en Paz Ciudadana, Santiago, 2011. En: http:// www.pazciudadana.cl/docs/pub_20110331091331.pdf, [visitado el 10/06/11].
} 
24,3\%, en los últimos cinco años de medición de este estudio ha reflejado una pequeña reducción, siendo del orden del $23,8 \%$; los delitos contra la propiedad mediante apoderamiento violento que se situaban a fines del decenio pasado en una media del $15 \%$, hoy se encuentran con una mayor representación, con un promedio de un $21 \%$.

\section{Delitos de tráfico ilícito de estupefacientes}

Sin lugar a dudas, la Ley de Drogas № 20.000, de 16 de febrero de 2005, y la ley a la cual ésta reemplazó, la № 19.366, vigente desde 1995, marcaron un hito y son claras representantes de lo que se debe entender por punitivismo penal.

Estas leyes no sólo han aumentado las penas de los delitos de tráfico de estupefacientes, sino que han flexibilizado las garantías fundamentales de los imputados sujetas a la misma. A su vez, el impacto que estas leyes ha procurado en la inflación carcelaria ha sido categórico. Así, sólo con la entrada en vigencia de la ley $\mathrm{N}^{\circ} 19.366$, los condenados prácticamente se triplicaron en su primer año, hasta casi quintuplicarse en el año 2004. Con la ley $N^{\circ} 20.000$, los condenados por ley de drogas han tenido un crecimiento sostenido desde su entrada en vigencia, siendo su momento cúspide y sin parangón, el año 2009, en que se registraron un total de 8.861 condenas, o, dicho de otra forma, mientras el año 1993 una de cada cien personas era condenada por estos delitos, el año 2009 este índice pasó a ser de quince personas.

Los cambios más significativos de la Ley de drogas y que colocarían a los condenados por esta ley en una situación más severa, debiendo cumplir penas privativas más largas a las que habían con antelación, tienen que ver con: la creación del delito de microtráfico; la mayor punición de las denominadas "drogas blandas", y la limitación de la atenuante prevista en el artículo 11 $N^{\circ} 7$ del Código Penal y las medidas alternativas a la privación de libertad.

El delito de microtráfico vino a dar solución a un problema de justicia material que existía hasta ese entonces. Los jueces, frente a aquellos supuestos de tráfico de pequeñas cantidades de droga y la consideración de las altas penas del delito de tráfico ( 5 años y un día a 15 años de prisión), optaban por sobreseer al imputado o recalificar el delito a la falta de consumo (sin pena privativa de libertad). ${ }^{51}$ Con ello, una serie de supuestos, por no decir la mayoría

\footnotetext{
${ }^{51}$ Ya, por ejemplo, en la discusión general de la ley № 20.000, el entonces Diputado Jaime Orpis, daba cuenta de este problema. Señaló en la Sesión 56, legislatura 343 de la Cámara de Diputados lo siguiente: "El tráfico de drogas está definido en el artículo $3^{\circ}$ de la ley № 19.366, pero su gran debilidad -o fortaleza; eso será parte del debate- es que no distingue entre el microtráfico y el gran tráfico que realizan las organizaciones criminales, y establece una penalidad común, entre cinco y quince años. Sin embargo, en la práctica -la gran debilidad-, los jueces, a las personas a las cuales se les encuentra en su poder pequeñas cantidades de droga, a través del subterfugio de la presunción, establecido en el inciso segundo, en lugar
} 
de situaciones que se dan en la vida real en relación a estos delitos, quedaban excarcelados o impedidos de una pena de prisión. Por lo tanto, este delito de microtráfico vino a llenar este vacío de punición y colocar en las cárceles a las personas que estaban bajo este supuesto, pero ahora, con una pena privativa de libertad que va de los 541 días a los 5 años. ${ }^{52}$

También estas leyes, y particularmente la ley $N^{\circ} 20.000$, pone término a la situación más benigna que se presentaba con el tráfico de las denominadas "drogas blandas", especialmente referida a la marihuana. Si antes de esta ley, el juez frente a estos supuestos podía rebajar la pena hasta en dos grados, ${ }^{53}$ ahora sólo lo puede hacer en un grado y siempre con carácter facultativo. Además, en muchas de sus disposiciones esta rebaja ni siquiera se contempla expresamente (Ej. arts. $\left.6^{\circ}, 7^{\circ}, 8^{\circ}, 10\right) .{ }^{54}$

Asimismo, estas leyes también pusieron término a otro fenómeno que acontecía en la práctica de los tribunales, el que decía relación con la posibilidad que los imputados por causas de drogas atenuaran su responsabilidad penal reparando el mal causado y, en consecuencia, cumpliesen penas más cortas. Estas leyes han impedido de manera crónica tal posibilidad al establecer la improcedencia de la atenuante contenida en el número 7 del artículo 11 del Código Penal. ${ }^{55}$

Para concluir, la Ley de Drogas impidió en una primera oportunidad-específicamente con la ley $\mathrm{N}^{\circ} 19.366$ - que los condenados por estos delitos fuesen beneficiados con la reclusión nocturna o libertad vigilada previstas en la ley № 18.216. Posteriormente, con la ley № 20.000 se morigeró esta situación, prohibiéndose estos beneficios sólo para los reincidentes en los delitos de la Ley de Drogas. ${ }^{56}$

\section{Delitos contra la propiedad}

Desde el paradigmático adelantamiento punitivo -se castigan como consumados delitos desde que se encuentren en grado de tentativa- de algunos delitos

\footnotetext{
de castigarlas como pequeños o microtraficantes, las consideran como consumidoras. En consecuencia, por no haberse aplicado la penalidad que corresponde, los traficantes pasaron a ser 'consumidores', siguieron traficando y, lo más delicado, las grandes organizaciones criminales se dieron cuenta de que el microtráfico es un canal eficaz de distribución de drogas y lo han utilizado hasta ahora".

${ }^{52}$ La existencia del delito de Microtráfico ha originado un exponencial aumento de la población carcelaria presa por este ilícito. En el año 2006 los presos no llegaban al 1\%; el año 2007 fue de 1,7\%; el 2008 fue de $3,6 \%$, y el 2009 de un 4,3\%.

${ }^{53}$ Véase art. $1^{\circ}$ de la ley $N^{\circ} 19.366$.

${ }^{54}$ Véase Politoff, Sergio; Matus, Jean Pierre; Ramírez, Cecilia, Lecciones de Derecho penal, $2^{a}$ Edición, Editorial Jurídica de Chile, Santiago, 2004, p. 577.

${ }^{55}$ Véase art. 32 de la derogada ley $\mathrm{N}^{\circ} 19.366$ y art. 20 de la ley $\mathrm{N}^{\circ} 20.000$.

${ }^{56}$ Véase art. 40 de la derogada ley № 19.366 y art. 62 de la ley № 20.000. Ambas normas sólo reconocían una excepción que estaba configurada por la cooperación eficaz.
} 
contra la propiedad, operado por el conocido artículo 450 del Código Penal, no se conocían otras modificaciones tendientes a agravar las penas de los delitos contra la propiedad y que tuviesen el designio de impactar positivamente en la población penal. Sin embargo, desde mediados de la década de los noventa, se han impetrado algunas modificaciones legales que, en nuestra opinión, han contribuido directamente a este escenario penal.

Es prueba de este fenómeno, la modificación ocurrida el año 1996: ${ }^{57}$ el delito de robo con fuerza en las cosas deja de tener una pena de 3 años y 1 día a 10 años, para consolidarse en una pena de 5 años y 1 día a 10 años; también se suprime la posibilidad que los encartados por delito de robo con violencia o intimidación en las personas, puedan ser acreedores de la atenuante prevista en el artículo $11 \mathrm{~N}^{\circ} 7$ del Código Penal, esto es, la posibilidad de reparar con celo el mal causado; las modificaciones legales impetradas el año 2004: ${ }^{58}$ mediante la cual, con carácter perentorio, se eleva la pena en un grado en los delitos de robo y hurto cuando los culpables hagan uso de armas o sean portadores de ellas. ${ }^{59}$ Asimismo, impone sanciones corporales para el delito de hurto de especies cuyo valor sea superior a media unidad tributaria mensual. Establece una pena de prisión para el delito de hurto falta de especies de un valor inferior a aquél. También establece la pena de prisión en su grado máximo para la reiteración del hurto falta; y, finalmente, modificaciones del año 2008: ${ }^{60}$ las cuales, si bien mantienen la penalidad del delito de receptación, amplían el espectro de situaciones que podrían caber bajo esta conducta. También se sanciona con penas elevadísimas que parten de los 541 días a los 5 años el robo y receptación de redes de suministro de servicios públicos o domiciliarios, tales como electricidad, gas, agua, alcantarillado, colectores de aguas Iluvia o telefonía.

\section{Tercer factor: Falta de instrumentos adecuados para LA DESCOMPRESIÓN DEL SISTEMA CARCELARIO}

En nuestro parecer, la legalidad vigente no otorga más que los beneficios de la ley $N^{\circ} 18.261$, el instituto de la libertad condicional y los beneficios

\footnotetext{
${ }^{57}$ Véase Ley № 19.449, de 8 de marzo de 1996, modifica el Delito de Robo y Hurto.

${ }^{58}$ Ley N N 19.975, de 5 de octubre de 2004, modifica el Código Penal en materia de Uso y Porte de Armas, y Ley № 19.950 de 5 de junio de 2004 que Aumenta Sanciones al Delito de Hurto y Facilita su Denuncia.

${ }^{59}$ Véase art. 450 inc. $2^{\circ}$ del Código Penal.

${ }^{60}$ Ley № 20.253, de 14 de marzo de 2008, que modifica el Código Penal en Materia de Seguridad Ciudadana, y Ley N ${ }^{\circ} 20.273$, de 28 de junio de 2008 sobre Delitos de Robo y Receptación de Cables Eléctricos y Tapas de Cauces.
} 
intrapenitenciarios para destrabar el uso de los recintos penitenciarios chilenos .

\section{Los beneficios alternativos a las penas privativas de libertad}

Los beneficios alternativos, son los contenidos y regulados en la ley № 18.216 que modificó la Ley № 7.821 sobre Remisión Condicional de la Pena, la cual establecía únicamente esta institución, aplicándola básicamente a condenados por delitos de poca gravedad y que presentaban escasa peligrosidad.

Esta nueva ley, incorpora dos nuevas instituciones además de la existente remisión condicional que, a pesar de su nombre, es una simple suspensión de la pena. Las nuevas medidas mencionadas son la reclusión nocturna y la libertad vigilada. La primera, consiste en el encierro en centros abiertos, desde las 22 horas de cada día hasta las 6 horas del día siguiente; la segunda consiste, al igual que la remisión condicional, en una suspensión de la ejecución de la pena, pero se diferencia de ella en que lleva consigo un tratamiento intensivo e individualizado en el medio libre. ${ }^{61}$

De una lectura de la Tabla 9, se desprende que en términos absolutos, las personas beneficiadas por la ley $N^{0} 18.216$ (Remisión condicional, Reclusión nocturna y Libertad vigilada) entre los años 2000 y 2009, ha aumentado en un $65 \%$.

No obstante, y a pesar de lo decidoras que puedan parecer estas cifras, esto no es sinónimo de que los jueces que ejercen competencia en materia penal están haciendo un mayor uso de este régimen alternativo al del cumplimiento de las penas privativas de libertad. Para poder conocer si estas medidas se han aplicado de manera decreciente, estable, o ascendente en distintos intervalos de tiempo, es menester conocer su tasa o frecuencia relativa, es decir, cuántas personas por cada $100 \mathrm{mil}$, en el año respectivo, fueron beneficiadas por esta ley. Así las cosas, podemos advertir que luego de un comienzo decreciente entre los años 2000 y 2005, donde la utilización de este régimen alternativo muestra un variación negativa del orden del 21,2\%, a partir del año 2006 hasta el final del período se advierte un ascenso constante, anotando una variación del $91,1 \%$, obteniendo una tasa nunca antes vista en la evolución de estas medidas penales, de 309,8.

${ }^{61}$ SAlinero, "Incidencia", cit. nota n. 32, p.17. 
Tabla 9. Evolución de Población beneficiada por ley Nº 18216 entre 2000-2009

\begin{tabular}{|l|l|l|l|l|}
\hline Año & Condenados & ley $\mathrm{N}^{\circ} 18.216$ & Tasa & Índice (\%) \\
\hline 2000 & 64.749 & 31.699 & 205,9 & 48,9 \\
\hline 2001 & 64.433 & 30.813 & 197,8 & 47,8 \\
\hline 2002 & 63.640 & 28.739 & 182,5 & 45,1 \\
\hline 2003 & 64.918 & 28.587 & 179,6 & 44 \\
\hline 2004 & 63.969 & 27.595 & 171,5 & 43,1 \\
\hline 2005 & 63.402 & 26.369 & 162,1 & 41,5 \\
\hline 2006 & 71.761 & 32.344 & 196,8 & 45 \\
\hline 2007 & 87.431 & 43.829 & 264,1 & 50,1 \\
\hline 2008 & 97.854 & 48.495 & 289,3 & 49,5 \\
\hline 2009 & 103.352 & 52.429 & 309,8 & 50,7 \\
\hline
\end{tabular}

Fuente. Elaboración propia de los datos obtenidos del Ministerio del Interior de Chile. División Seguridad Pública.

Asimismo, la columna "Índice", 62 nos informa el total de beneficiados en consideración al total de condenados en el año respectivo. En tanto más alto el índice, mayor será la tasa de excarcelados por beneficios. A la inversa, mientras más bajo el índice, mayor será el número de encarcelados sin beneficios. En concreto, se advierte que a partir de su mayor utilización en 2006, mayor ha sido la cantidad de excarcelados y beneficiados.

En síntesis, desde una perspectiva histórica no existe un uso reducido de los beneficios previstos en la ley $N^{\circ} 18.216$. Tampoco en virtud de ello se puede justificar per se el incremento de la población carcelaria. Ahora bien, lo que no se sabe y no podremos saber con estas cifras, es de si están beneficiados por esta ley, todos los que cumplen, a lo menos, los requisitos objetivos para ser acreedores de este régimen alternativo a la prisión efectiva.

\section{Reducción en el otorgamiento de la libertad condicional}

En general, la libertad condicional es un beneficio legal que se concede por orden del Presidente de la República a personas condenadas a penas privativas de libertad superiores a 1 año, con el fin que cumplan en libertad el saldo de la pena impuesta y estén sujetas a determinadas condiciones de control. ${ }^{63}$

\footnotetext{
${ }^{62}$ Esta columna representa el porcentaje de beneficiados conforme a la ley № 18.216 en relación al total de condenados a penas privativas de libertad en el año respectivo. No se consideran los condenados a penas de multa.

${ }^{63}$ La libertad condicional está regulada en el decreto ley № 321, del año 1925.
} 
Tabla 10. Evolución de la Libertad Condicional en Chile entre 2000-2009

\begin{tabular}{|l|c|c|}
\hline Año & Libertad Condicional & Tasa \\
\hline 2000 & 1.836 & 11,9 \\
\hline 2001 & 1.699 & 10,9 \\
\hline 2002 & 1.472 & 9,3 \\
\hline 2003 & 1.463 & 9,1 \\
\hline 2004 & 1.267 & 7,8 \\
\hline 2005 & 850 & 5,2 \\
\hline 2006 & 767 & 4,6 \\
\hline 2007 & 892 & 5,3 \\
\hline 2008 & 554 & 3,3 \\
\hline 2009 & 347 & 2 \\
\hline
\end{tabular}

Fuente. Elaboración propia a partir de los datos de Gendarmería de Chile (Memoria Anual de Gendarmería).

A la luz de la Tabla 10, es totalmente evidente el descenso que han tenido las autoridades en el otorgamiento de la libertad condicional. En el periplo 2000-2009, la caída en términos absolutos y relativos está por sobre el 500\%. Mientras en el año 2000 se otorgaron 1.836 libertades condicionales, en el año 2009 sólo se concedieron 347. ${ }^{64}$ En torno a este punto, es elocuente el trabajo de Sepúlveda Crerar y Sepúlveda Basaez, titulado "A 83 años del establecimiento de la libertad condicional en Chile: ¿Un beneficio desaprovechado?", donde concluyen, sin más, el dramático descenso y desconfianza que ha tenido esta institución desde su origen. ${ }^{65}$

De una lectura especulativa de la causa de estos resultados, sin duda podría ser atribuida a lo que Garland describe como el cambio de enfoque de los agentes encargados del control de la criminalidad y de la justicia penal: asentamiento de una Criminología basada en el control social; una política criminal de tolerancia cero y simbólica; punitivismo por sobre el ideal rehabilitador, etc. ${ }^{66}$ Esto significa en nuestro opinión, que la cárcel es una todo poderoso frente al ideal rehabilitador. Ante la ausencia vox populi de esta última, la cárcel es la única medida certera de seguridad que la sociedad reclama.

\footnotetext{
${ }^{64}$ Otros estudios dan cuenta del uso restringido de la libertad condicional y cómo ésta ha incidido en el incremento de la población penal. Álvarez; Marangunic; Herrera, "Impacto", cit. nota n. 21, p. 128 y ss. También, Fundación Paz Ciudadana, "Recomendaciones para una nueva política penitenciaria", Santiago, marzo, 2010, p. 128 y ss. En: http://www.pazciudadana.cl/docs/pub_20100319142517.pdf [visitado el 10/06/11].

${ }^{65}$ Sepúlveda Crerar, Eduardo; Sepúlveda Basaez, Paulina, "A 83 años del establecimiento de la libertad condicional en Chile: ¿Un beneficio desaprovechado?", Rev. Estudios Criminológicos y penitenciarios. Año VIII, N¹3 - diciembre 2008, pp. 85-110.

${ }^{66}$ Garland, David, La cultura del control Crimen y orden social en la sociedad contemporánea, traducido por Sozzo Máximo, Gedisa, España, 2005.
} 
Ahora bien, la libertad condicional es un mecanismo de descongestión carcelaria que no tiene el impacto que debiese, y esto es la consecuencia de su reducida utilización. En países como España, esta herramienta que ha mediados de la década pasada favorecía al $25 \%$ de la población penal y en la presente década ayuda al $10 \%$ de la misma, ${ }^{67}$ no tiene comparación con lo que ocurre en nuestra criolla realidad, en donde ni siquiera se concede la libertad condicional al $1 \%$ de la población reclusa.

\section{Beneficios intrapenitenciarios}

Estos beneficios forman parte de las actividades de reinserción social y confieren a quienes se les otorgan gradualmente, mayores espacios de libertad. Estos son los denominados permisos de salida (salida esporádica, salida dominical, salida de fin de semana y salida controlada al medio libre). ${ }^{68}$

Estos beneficios son una importante herramienta con que cuenta la Administración central para desacopiar internos desde las cárceles chilenas. Sin embargo, el uso de estos instrumentos, y en particular, de la salida controlada al medio libre que permite, según las circunstancias, una salida permanente del reo desde los penales, no ha sido del todo lo que se podría esperar.

Tabla 11. Evolución de la Salida controlada al medio libre entre 2000-2009

\begin{tabular}{|l|l|l|l|}
\hline Año & Salida Controlada & Tasa & Índice \\
\hline 2000 & 673 & 4,3 & 2 \\
\hline 2001 & 748 & 4,8 & 2,2 \\
\hline 2002 & 886 & 5,6 & 2,5 \\
\hline 2003 & 941 & 5,9 & 2,6 \\
\hline 2004 & 878 & 5,4 & 2,4 \\
\hline 2005 & 735 & 4,5 & 2 \\
\hline 2006 & 638 & 3,8 & 1,6 \\
\hline 2007 & 715 & 4,3 & 1,6 \\
\hline 2008 & 813 & 4,8 & 1,6 \\
\hline 2009 & 828 & 4,8 & 1,6 \\
\hline
\end{tabular}

Fuente. Elaboración propia a partir de los datos de Gendarmería de Chile (Memoria Anual de Gendarmería).

\footnotetext{
${ }^{67}$ CID Moliné, José, “El incremento de la población reclusa en España entre 1996- 2006: Diagnóstico y remedio", en Revista Española de Investigación Criminológica No 6 (2008), pp. 1-31. Para un estudio comparativo, entre la realidad penitenciaria chilena y española, también puede revisarse: DíAz VILLAVICENCIO, Guillermo. "Comparación penitenciaria entre Chile y España: Un enfoque económico". Revista Estudios Criminológicos y Penitenciarios, № 16 (2010), pp. 71-95.

${ }^{68}$ Véase artículos 96 y ss. del decreto $N^{\circ}$ 518, de 21 de agosto de 1998, conocido como Reglamento Penitenciario.
} 
En el último decenio, la variación absoluta como relativa ha sido, más bien, mínima. El índice de las personas beneficiadas por este instrumento intrapenitenciario en relación a la población penal del respectivo año ha sido permanentemente casi el mismo, arrojando un promedio total de 2,1\%. Esta cifra sin duda es marginal, y sólo demuestra probablemente, no sólo la desconfianza de los actores penitenciarios en esta medidas, sino la falta de una política penitenciaria en su uso.

\section{CONCLusiones}

Una proposición ineludible a la que podemos llegar luego de haber establecido las premisas anteriores, plausiblemente acreditadas en forma empírica, es que el incremento exponencial de la población carcelaria chilena, no es un problema del último decenio, sino que es una cuestión que nos afecta, a lo menos, desde la década de los ochenta hasta nuestros tiempos. Como señalamos, sólo en la década del ochenta el incremento de la población carcelaria fue de un $65 \%$, en circunstancias que la población chilena sólo tuvo un incremento nominal de un $16 \%$. En la década de los noventa la variación carcelaria total del período fue de un $33 \%$, siendo el crecimiento poblacional sólo de un 16,5\%. Para qué hablar de los últimos diez años, donde el alza de la población carcelaria ha sido en un porcentaje no inferior al 54\%, en circunstancias que nuestra población creció en el orden del 11\%.

Otra conclusión, es que estimamos que existen tres factores conducentes al incremento carcelario. El primero, es la existencia de un mayor flujo de ingresos al sistema penitenciario que no guardaría la debida correspondencia con las personas que egresan del mismo sistema. El segundo factor, es el hecho que algunas personas, para determinados delitos, ingresarían al sistema penitenciario y permanecerían largos tiempos de privación libertad en comparación a lo que sucedía en décadas pasadas. El último factor, el que está conexo de alguna manera con los anteriores, es la falta de mecanismos eficientes que ayuden descomprimir el sistema carcelario.

A su vez, los factores referidos anteriormente, estarían motivados por una serie de causas que los producirían.

De esta manera, es probable que el mayor ingreso de personas al sistema penitenciario esté dado por la entrada en vigencia de la Reforma Procesal Penal y por algunas leyes que favorecen la encarcelación. La reforma no sólo creo un nuevo proceso penal o cambio al antiguo sistema inquisitorio, sino que estableció un nuevo management en lo que a administración de justicia penal se refiere, asentando en nuestra sociedad una nueva estructura orgánica de control del delito que ha permitido cuantitativa y cualitativamente mayores ingresos y mayores términos de los procesos judiciales, lo cual, por lo demás, 
no es sinónimo de eficiencia en los resultados finales, tanto para víctimas, imputados y la sociedad como persona demandante de justicia; la reforma también creo una justicia acelerada, que ha permitido resolver las cuestiones puestas en su conocimiento, en tiempos que son insuperables para la justicia antigua. Un poco más del $80 \%$ de los procesos que ingresan a los tribunales son terminados antes de los seis meses y sólo un poco más del $5 \%$ terminan después del año; también la reforma aumentó considerablemente la tasa de condenas. Desde el año 2006, la tasa prácticamente se cuadruplicó frente a lo que existía en el ocaso del sistema inquisitivo. Como si esto fuese menor, en el año 2009, las cifras se cuadruplicaron nuevamente frente a las ya mencionadas del año 2006; también la reforma creó los denominados procesos de auto incriminación -simplificado y abreviado-, los que estimamos han calado hondo en el aumento de la población penal y, quizás, más con la entrada en vigencia de la ley No 20.074, que vino a agilizar la persecución penal, evitando zonas de impunidad, y corregir los errores normativos de los procedimientos de autoincriminación detectados en la puesta en marcha de la reforma en Regiones. Estos procedimientos han tenido un incremento sostenido, favoreciendo la imposición rápida y negociada de una pena, que en una gran cantidad de casos será de cumplimiento efectivo y además permiten presumir fundadamente que colaboran estrechamente con la punición efectiva de la eventual segunda condena, en los casos de reincidencia. También, hemos dicho que sería una causa del mayor ingreso de personas a los penales, ciertas leyes que facilitan de manera directa la prisionización. Esta tendencia está marcada por una política criminal de "tolerancia cero" que impera en nuestra sociedad y por el carácter que tiene la prisión como única respuesta penal. Creemos que serían prueba de este fenómeno pro-cárcel, la sustitución por la prisión de la pena de multa impaga y los denominados delitos dentro del contexto de la violencia intrafamiliar. La sustitución de la pena de multa por la prisión concentra un índice importante de personas privadas de libertad dentro de la geografía carcelaria y que, a lo mejor, muchas de ellas tendrían la posibilidad de un beneficio alternativo a la prisión en el evento que hubiesen sido condenados a una pena de prisión y no de carácter pecuniario. Situación de extrema falta de coherencia a la luz de los fines de las penas y de las necesidades de despoblar cárceles chilenas; otra causa estaría constituida por los delitos de violencia intrafamiliar que, además de endurecer sus penas, han tenido un incremento en sus judicializaciones. Estos delitos, de alguna manera, quizás por motivos del espacio que han ganado en los medios de comunicación, han favorecido la prisión preventiva (algo más de 1000 personas el año 2010) y el alza exponencial de los personas condenadas por los mismos.

Ahora bien, en lo tocante a las causas que producen que los ingresados al sistema penal permanezcan mayores tiempos sirviendo una pena, las podríamos 
reducir a ciertas leyes que han agravado la punición de ciertos y determinados delitos muy bien representados en el contorno penitenciario. Serían prueba de ello, las modificaciones que han sufrido los delitos contra la propiedad y los de tráfico ilícito de estupefacientes, con una presencia actual de un $45 \%$ los primeros (en la década de los noventa era de $40 \%$ ) y de casi un $10 \%$ los segundos (en la década de los noventa era de $8,5 \%$ ).

Por último, la inadecuada descompresión del sistema carcelario encuentra, a nuestro juicio, sus causas en el uso restringido de la libertad condicional y en la falta de otros instrumentos que cumplan con dicha finalidad.

De seguir con la actual política criminal y con la carencia de un sistema alternativo a la prisión como única consecuencia del delito, seguiremos en la misma senda, en la que necesitaremos más cárceles para recibir a más presos, con la subsecuente falta de recursos y sobrepoblación penal.

\section{BibLIOGRAFíA}

AEBI, Marcelo; KunN, André, "Influences on the prisioners rate: Number of entries into prison lenght of sentences and crime rate", European Journal on Criminal Policy and Research 8 (2000).

Álvarez Tuza, Pablo; Marangunic Hinojosa, Antonio; Herrera Bilbao, Raúl; "Impacto de la reforma procesal penal en la población carcelaria del país", en Revista de Estudios Criminológicos y penitenciarias 11 (2007).

Bascuñán Rodríguez, Antonio, "El robo como coacción", Revista de Estudio de la Justicia 1 (2002).

CAstillo VAl, Ignacio, La cárcel y la política criminal, Texto inédito, facilitado por su autor.

CID Moliné, José, "El incremento de la población reclusa en España entre 1996- 2006: Diagnóstico y remedio", en Revista Española de Investigación Criminológica № 6 (2008).

Dammert, Lucía; ZúÑIGA, Liza, La Cárcel: Problemas y desafíos para las Américas, Flacso, Santiago de Chile, 2008.

Díaz Villavicencio, Guillermo. Comparación penitenciaria entre Chile y España: Un enfoque económico Revista Estudios Criminológicos y Penitenciarios, $\mathrm{N}^{\circ} 16$ (2010), pp. 71-95.

FREY, Antonio, "Seguridad ciudadana, ambivalencia de las políticas criminológicas y privatización del sistema carcelario", Revista de la Academia 5 (2000).

Garland, David, La cultura del control Crimen y orden social en la sociedad contemporánea, traducido por Sozzo Máximo, Gedisa, España, 2005.

Garrido, Vicente; Stangeland, Per; Redondo, Santiago, Principios de Criminología, $3^{a}$ Edición, Tirant Lo Blanch, Valencia, 2006. 
Greenber, David, "Punishment, Division of Labor, and Social Solidarity", The Criminology of Criminal Law. Advances in Criminology Theory 8 (1999).

Horvitz Lennon, María Inés; López Masle, Julián, Derecho Procesal Penal Chileno, tomo I, Editorial Jurídica de Chile, Santiago, 2005.

Jakobs, Günther; Cancio Melí́, Manuel, Derecho penal del enemigo, $1^{\text {a }}$ Edición, Civitas, España, 2003.

LappI Seppala, Tapio, "Trust, Welfare, and Political Culture: Explaining Differences in National Penal Policies", The University of Chicago Crime and Justice 37 (2008).

Mathiesen, Thomas, Juicio a la prisión, traducción de Zamuner, Amanda, Ediar, Buenos Aires, 2003.

Morales, Ana María; Pérez, Pablo; Welsch, Gherman, "Caracterización de la población en prisión preventiva", en Paz Ciudadana, Santiago, 2011,

En: http://www.pazciudadana.cl/docs/pub_20110331091331.pdf.

Politoff, Sergio; Matus, Jean Pierre; Ramírez, Cecilia, Lecciones de Derecho penal, $2^{\circ}$ edición, Editorial Jurídica de Chile, Santiago, 2004.

Riego, Cristian, "El Proceso Penal Chileno y los Derechos Humanos", Cuadernos de Análisis Jurídico, volumen I, número 4, Serie Especial (1994), Facultad de Derecho de la Universidad Diego Portales.

RudDELl, Rick, "Social Disruption, State Priorities, and Minority Threat: A CrossNational Study of Imprisonment", Punishment and Society: The International Journal of Penology 7 (2005).

Salinero, Sebastián, "Incidencia de la Probabilidad de Condena en los Delitos de Robo. Análisis Descriptivo y Comparado", Política Criminal 8 (2009), [http://www.politicacriminal.cl/Vol_04/n_08/Vol4N8A5.pdf].

Sepúlveda Crerar, Eduardo; Sepúlveda Basaez, Paulina. "A 83 años del establecimiento de la libertad condicional en Chile: ¿Un beneficio desaprovechado?", Rev. Estudios Criminológicos y penitenciarios. Año VIII, Nº13 - diciembre 2008, pp. 85-110.

Silva SÁnchez, Jesús María, La expansión del derecho penal. Aspectos de la política criminal en las sociedades postindustriales, 2a Edición, Civitas, España, 2001.

Stangeland, Per, "Encuestas de Victimización", en Díez Ripollés, José Luis; Cerezo Dominguez, Ana Isabel (editores), Los Problemas de la Investigación Empírica en Criminología: La situación española, Tirant Lo Blanch, Valencia, 2001.

Sutton, John, "The Political Economy of Imprisonment in Affluent Western Democracies, 1960-1990", American Sociological Review 69 (2004). 
VAN DIJK, Teun, The Burden of crime in the E.U. 2005 En: www.europeansafetyobservatory.eu/

Von Hofer, Hanns, "Prision Populations as Political Constructs: The case of Finland, Holand and Sweden", Journal of Sandinavian Studies in Criminology and Crime Prevention 4 (2003). 
